
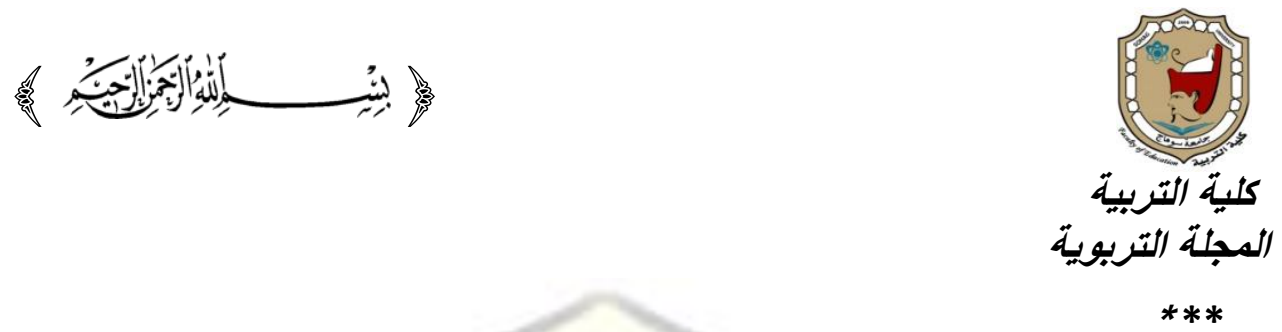

\title{
اليقظة العقلية وعلاقتها بأعراض القلق لدى طلاب الكلية التقنية بمحافظة بيشة
}

\section{إعداد - (إد}

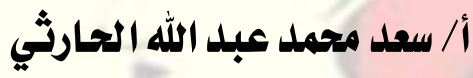

باحثت ماجستير في الإرشاد النفسي

$$
\text { المجلة التربوية.العدد السابع والخمسون.يناير 19.rora }
$$

Print:(ISSN 1687-2649) Online:(ISSN 2536-9091) 
هدفت الدراسة إلى التعرف على درجة كل من اليقظة العقلية وأعراض القلق والعلاقة بينهما لاى طلاب الكلية التقتية بمحافظة بيشة، واتبعت الدراسة المنهج الوصفي بصورته التهاته

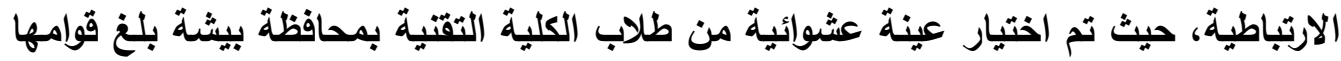

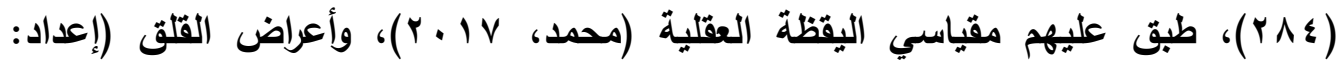
الباحث)، وقد توصلت الدراسة إلى مجموعة من النتائج كان من أبرزها: وجود علاقة ارتباطية

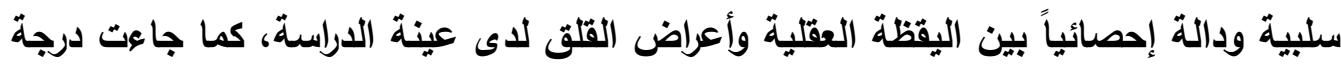

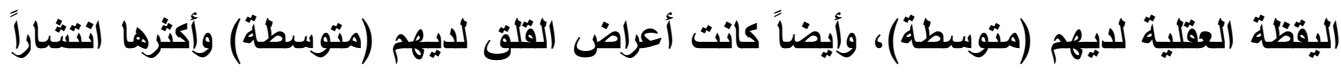

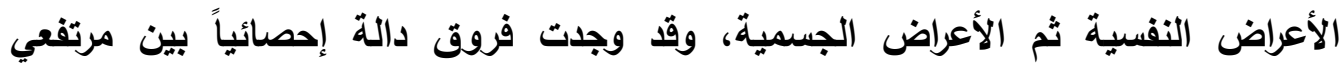

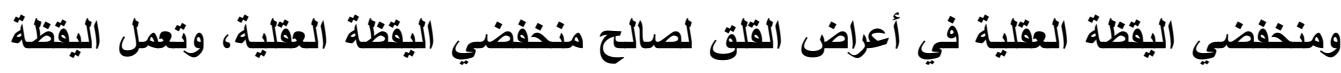

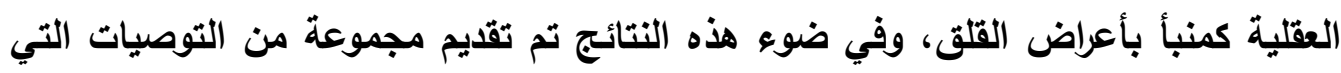

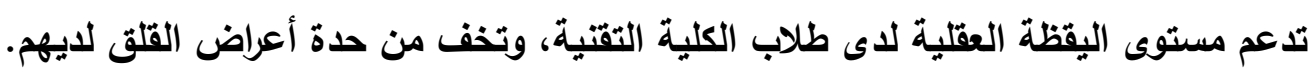

The study aimed at identifying the degree of mindfulness and its relation to anxiety symptoms among technical college students at bisha governorate, the study followed the descriptive method in its associative form. A random sample of 284 students was selected for the Technical College in Bisha Governorate. The mindfulness measurements (Mohammad, 2017) were applied to them and the symptoms of concern were determined by the researcher. The most prominent among them were negative correlation and statistical function between mindfulness and anxiety symptoms in the study sample, as well as their mindfulness (mean), anxiety symptoms (moderate), and most prevalent psychological symptoms and physical symptoms. There were statistically significant differences Between high and low mindfulness in a Satisfied with concern in favor of low mindfulness, mindfulness and working as a predictor of symptoms of anxiety, and in the light of these findings were presented a set of recommendations that support mental alertness level of technical college students, and ease the severity of symptoms of anxiety they have. 


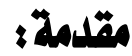

شباب اليوم هم حاضر الأمة ومستقبلها، وعليهم تقع مسؤولية النهوض بمجتمعاتهم، وهذا ما أوجب على القائمين بالأمر الاهتمام بالمرحلة الجامعية وطلابها، فتثقيف الثباب في مرحلة ما بعد التعليم العام وتدريبهم وتأهيلهم نفسياً يساعدهم على المضي في الحياة بخطى العائ ثابتة؛ بحيث تكون شخصياتهم سوية وسلوكهم إيجابي، على النحو الذي يمكنهم من مواجهة الحياة ومتطلباتها بطريقة إيجابية، خالية من الأعراض المرضية. ويرتبط ظهور هذه الأعراض المرضية لدى الثباب بتعرضهم لمواقف مُشكلة، فعندما يواجه الفرد صعويات أو إحباطات، فإن ذلك ما يعيق قدرته على الإنجاز فيشعر بالإحباط، لئل ومثل هذا الثعور يُعد عائقاً أما الطلاب في سبيل وضع أهداف مستقبلية ذات قيمة، فيسعون التهان حينئذ إلى تحقيق انجازات قصيرة المدى، ويالتالي يقل شعورهم بالهناءة النفسية، وتبدأ أعراض القلق في الظهور لايهم (Browen, 2011, 12). ويُعدّ القلق القاسم المشترك في الاضطرابات النفسية، حيث يُلاحظ لاى طلبة العدارس والجامعات خلال الفترة التي تسبق الامتحان، أو عند تعرضهم لمواقف محبطة، فتئخذ أعراضه

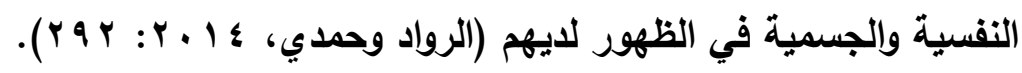

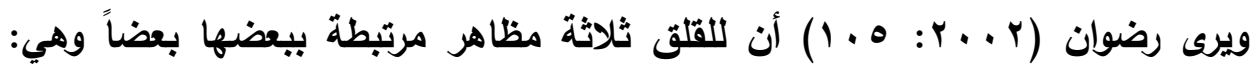
المظهر الجسدي؛ ويبدو في تسارع دقات القلب والتعرق وتوتر العضلات، والمظهر الانفعالي

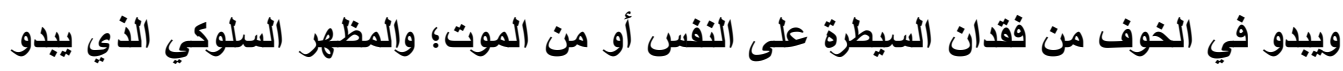
في الهرب وتجنب المواقف الحرجة. وتكمن خطورة القلق فيما له من تأثير كبير على الأفراد بدءاً من التأثير على معدلات

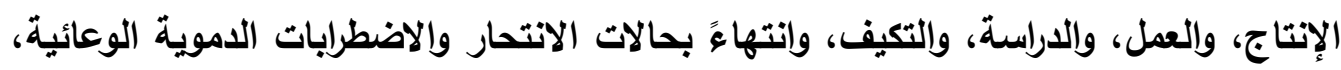

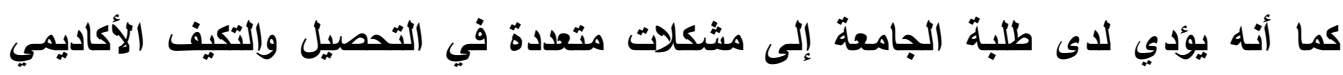
.(Uludag, 2014, 504) ولذا وُجد توجه لدى الباحثين نحو العمل على دراسة المتغيرات التي تحد من شعور

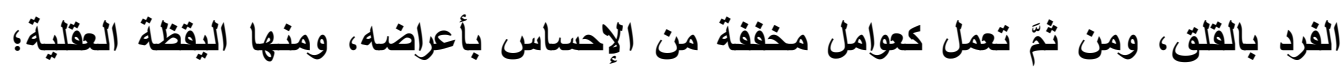

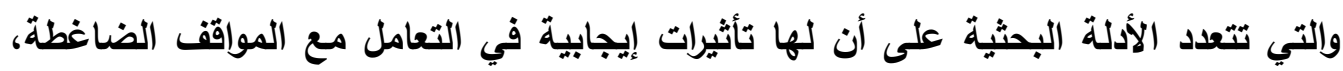
حيث بأت الدراسات تنتبه إلى العمليات التي ريما تساعد على شرح تأثيراتها، وتتضمن 
العمليات المقترحة تغييرات في استخدام كل من: الانتباه، والمعرفة، والمشاعر، والاستبصار، والمواجهة، وعدم التعلق، وريما تؤدي هذه العمليات بشكل مباشر أو غير مباشر باستخدام اليقظة العقلية إلى نتائج مفيدة (Brown\& Ryan, 2007, 72). Meta- Cognitive ما يمكن استخدام اليقظة العقلية لتنمية وعي ما وراء المعرفة Awareness إدراك أنها واقع مطلق؛ والتي نحتاج للعمل بموجبها لمواجهة المشاعر السلبية، وتثجيع الفرد على تطوير منظور (Hasker, 2010, 4). كما أن التذخلات المبنية على اليقظة العقلية تستخدم في تطبيقات عديدة لإرشاد حالات نفسية عديدة، ومنها: المزاج (القلق والاكتئاب)، والهلوسات، والسلوكيات (الشره العصبي، الإدمان، إيذاء الذات، العنف)، ومشكلات التعلق (الاتجاهات، التعاطف)، ومشكلات الذات

.(Mace, 2008, 58)

كذلك توجد أدلة بحثية متعددة على أن توظيف اليقظة العقلية يساعد كثيراً من الأفراد على التصالح مع ذاتهم وخاصة الذين يعانون من ضغوط، واضطرابات صورة الجسد، وخفض القلق والاكتئاب (Grow, Collins, Harrop\& Marlatt, 2015, 17). ومن هذا المنطلق جاعت فكرة الدراسة الحالية، والمتعلقة بالبحث في طبيعة العلاقة بين اليقظة العقلية وأعراض القلق لدى طلاب الكلية التقنية بمحافظة بيشة.

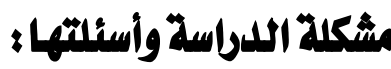

تعثبر مرحلة المراهقة المتأخرة إحدى المراحل النمائية المهمة في دورة حياة الفرد، التي تسهم بشكل كبير في تثكيل جوانب شخصيته المختلفة من خلال ما يحدث فيها من مواقف، وما يعتريها من تغيرات قد تؤدي في النهاية إما إلى شخصية سوية متكاملة تتمتع بالتوافق ويالصحة النفية، أو إلى شخصية مضطرية قد تلجأ إلى أساليب تكيف غير سوية.

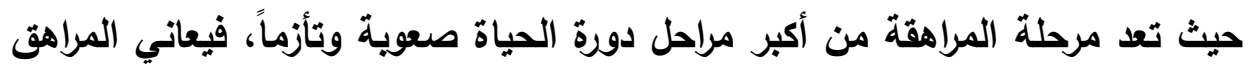
أثناءها حالة من القلق والاضطراب النفسي وارتباك الهوية، وذلك في أثناء محاولاته المختلفة لاستكشاف الذات والعالم الخارجي، والبحث عن الهوية الثخصية، حيث تثير نتائج بعض الدراسات أن تعرض المراهقين لبعض الصدمات النفسية والصراعات والمشكلات المتنوعة قد تؤدي إلى ظهور العديد من الأعراض المرضية لديهم (الهواري، 10 ـ ب: ؛ V). 
وفي ظل هذا الإحساس المتزايد بخطورة ما يتعرض له المراهقون من مشكلات

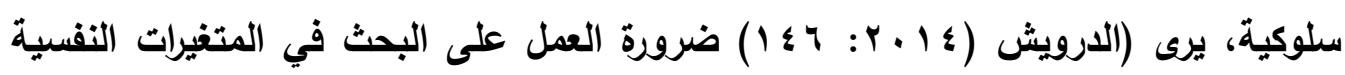

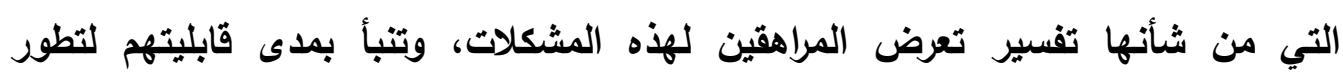
الأعراض أو قرتهم على الصمود في مواجهتها.

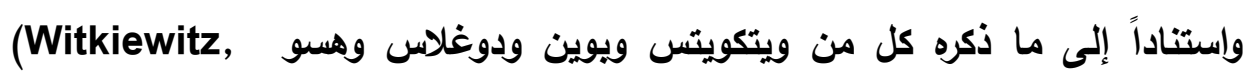
فowen, Douglas\& Hsu, 2013: 1564 في المواقف الضاغطة، ومنها المواقف الحادثة في البيئة الدارسية، فإن مشكلة الدابلة الداسة

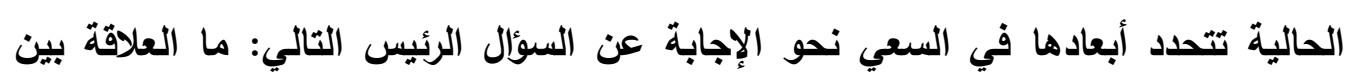
اليقظة العقلية وأعراض القلق لاى طلاب الكلية التقتية بمحافظة بيثة الإنج ويتفرع من هذا السؤال الرئيس، مجموعة الأسئلة البحثية التالية:

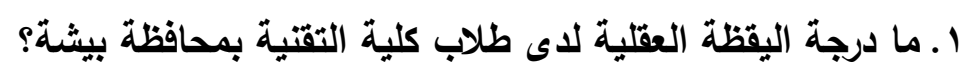

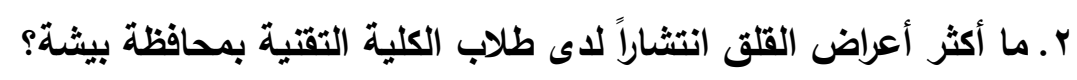
r.r. ما دلالة الفروق الإحصائية عند مستوى دلالة (1)

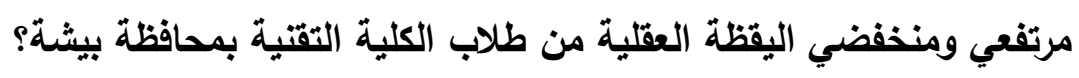

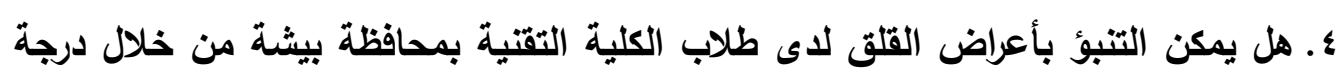

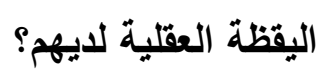

أهداض الدراسةخا

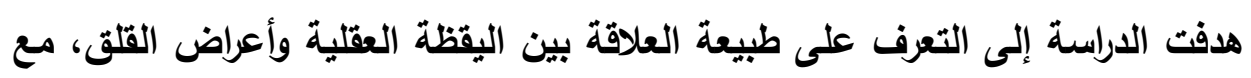

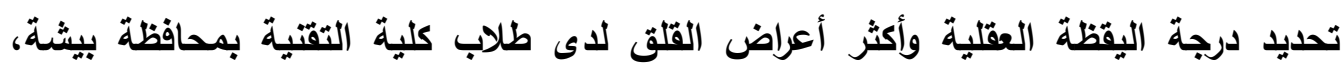

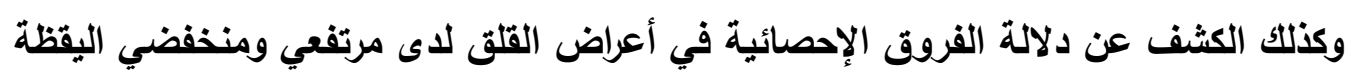

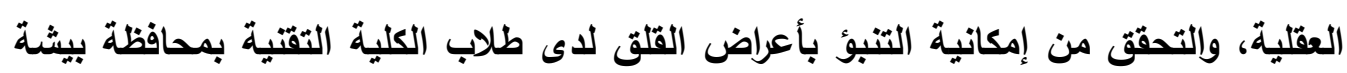
من خلال درجة اليقظة العقلية لايهم.

أهمية اللدراسة

أولأ الأهية النظرية.

تكتسب الدراسة الحالية أهميتها النظرية من خلال إلقاء الضوء على ظاهرة إنسانية

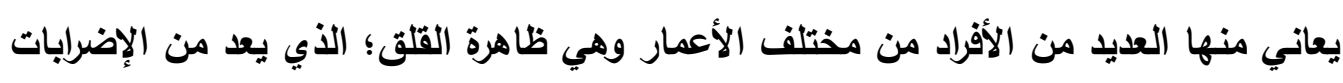


التي تؤدي إلى التأثير على صحة الفرد وإنتاجيته، كذلك إثراء المجال الإششادي بأدب نظري عن اليقظة العقلية لما لها من دور في توجيه انفعالات وأفكار الفرد في المواقف الضاغطة. ثانياً: الأهمية التطبيقية. يُؤمل أن الدعم والمساعدة لكل من أولياء الأمور والمرشدين والمدرسين والمربين في توفير البيئة المناسبة لمواجهة القلق والمساعدة على نمو مستوى إيجابي من اليقظة العقلية لاى طلاب التعليم عامةًَ، والتعلم الجامعي.

\section{حلدود الثداسةح:}

تتحدد الاراسة الحالية بمجموعة المحددات التالية:

ا ـ الدود الموضوعية: اقتصرت الدراسة الحالية على تناول متفيري اليقظة العقلية، وأعراض

r ـ الحدود البشرية: طلاب الكلية التقتية في أقسامها المختلفة. r. الحدود المكانية: تم تطبيق أداة الدراسة على عينة من طلاب الكلية التقتية بمحافظة بيشة.

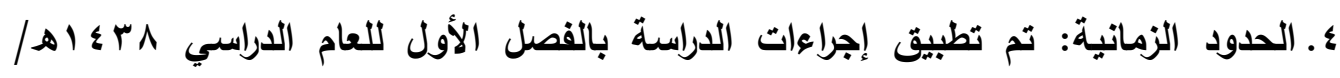
. 1 ( 1 \%

\section{الأدب النظري لمتفيرات الدراسة}

تناولت الدراسة الحالية متغيرين رئيسين، يمكن التأصيل لهما على النحو التالي:

\section{: Mindfulness اليقمطة المقلية}

Langer, 1992, ) في سياق تعريف اليقظة العقلية- كمفهوم نفسي- يعرفها لانجر 4) بأنها "مجال مرّن للقدرة العقلية يكون غير مرتبط بوجهة نظر خاصة، ويسمح بروئية جيدة ومنفتحة على كل الخبرات العقلية والحسية للشخص، ومن دون إصدار أحكام".

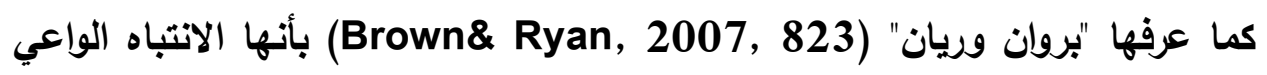
الموضوعي في اللحظة الحاضرة. كما تعني اليقظة العقلية من وجهة نظر نيف (Neff, 2003, 232) بأنها "حالة من الوعي المتوازن الأي يجنب الفرد النقيضين من التوحد الكامل بالهوية الأتية، وعدم الارتباط بالخبرة، ويتبع روئية واضحة لقبول الظاهرة النفسية والانفعالية كما تظهر. وتعني أيضاً 


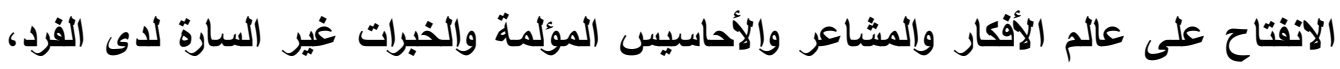
ومعايشة الخبرة في اللحظة الحاضرة بشكل متوازن".

وتتضمن اليقظة العقلية الوعي والانتباه والتركيز على الأحداث الإيجابية أو السلبية في

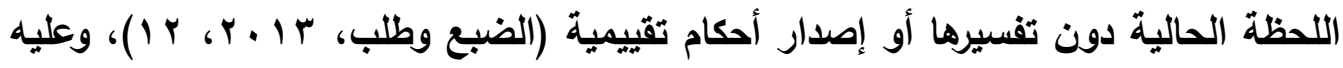

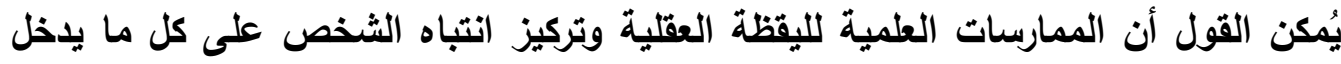
لخبرته في الوقت نفسه يسمح للثخص بالتحقق من كل ما يدور من حوله دون الوقوع في

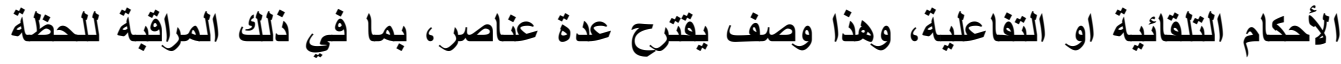
الممارسة الحالية للتجرية الى الوقت الحاضر (Baer, at el., 2006, 28)، فيما ذكر هاسكر (Hasker, 2010, 12) مكونين رئيسيين لليقظة العقلية وهما: التنظيم الذاتي للانتباه Self- Regulation of attention في اللحظة الحالية، والانفتاح والاستعداد والوعي بالتجارب في اللحظة الحالية. In: Bernay, 2009, ) May وترتبط أهمية اليقظة العقلية بمبادئ سبعة حددها مائهائ 4) والتي تُمثل مجموعة من الأنثطة التي إذا ما انخرط فيها الفرد فإنها ستحفز الذهنه

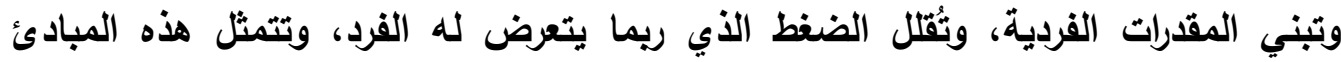

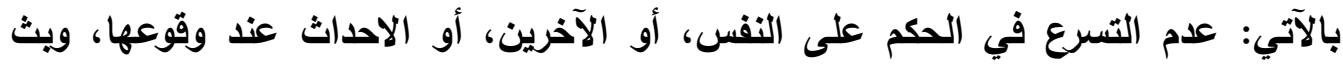

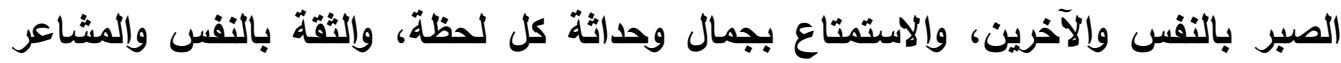

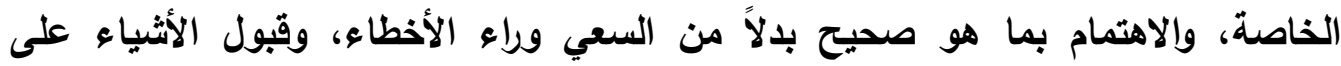
حقيقتها كما هي، وليس كما يصورها الآخرون، وترك الأمور المسلم بها والتخلي غنها.

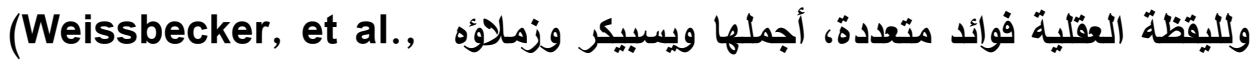
(2002, 299 في الآتي: تعزيز الثعور بالقدرة على إدارة البيئة المحيطة من خلال تعزيز

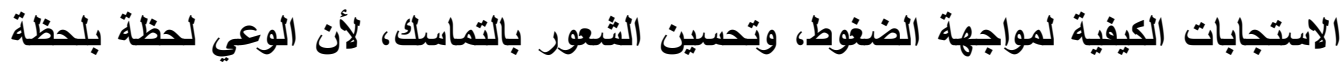

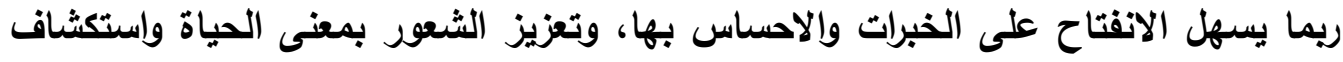
المعنى. وتتطلب اليقظة العقلية من الثخص الثفقة بنفسه ومراقبة أفكاره ومشاعره السلبية

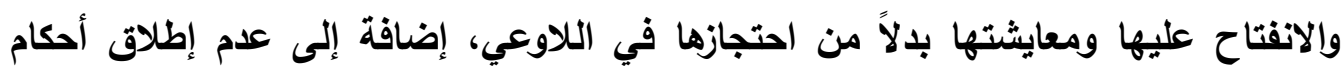

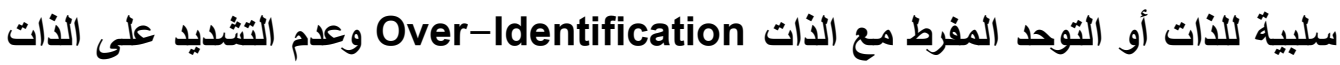




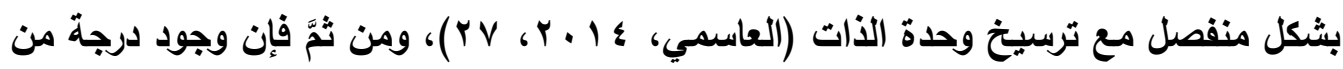
اليقظة العقلية يسهم بثكل مباشر في عنصرين: عدم إصدار الأحكام، والنقا الذاتي، وزيادة

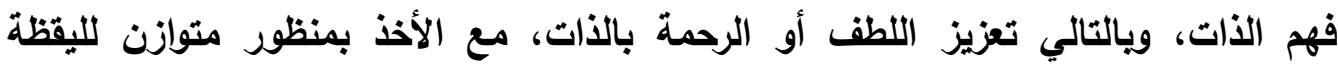
العقلية، وذلك للابتعاد عن العزلة والأنانية واللذان يُعدان من الأسباب النفسية الرئيسة للإقبال (Shorey, Elmquist, Wolford-Clevenger, Gawrysiak, على الإدمان

.Anderson\& Stuart, 2016, 122) وهناك أدلة بحثية متعدة على أن توظيف اليقظة العقلية يساعد كثيراً من الأفراد على

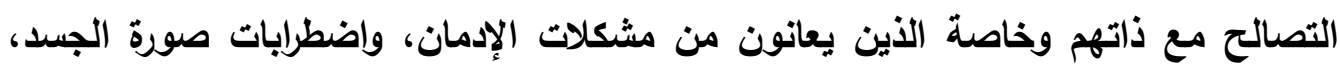
وخفض القلق والاكتئاب (Grow, Collins, Harrop\& Marlatt, 2015, 17)، كما (Witkiewitz, Bowen, Douglas\& Hsu, يذكر ويتكويتس ويوين ودوغلاس وهسو

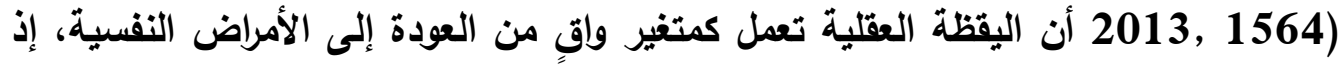
تعمل على التخفيف من حدة الأعراض المرضية. ومن الدراسات التي تناولت اليقظة العلاقية في علاقتها بعدد من المتنغيرات النفسية، دراسة أبينج وديوفيناج (Pepping\& Duvenage, 2016) والتي هدفت إلى دراسة فئس الفروق في مستوى اليقظة العقلية لاى المراهقين من الجنسين في المرحلة الجامعية وفقاً

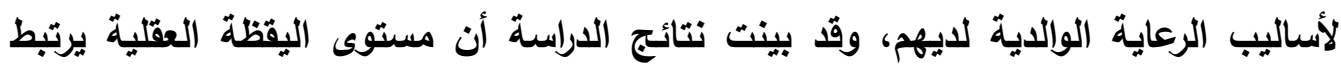

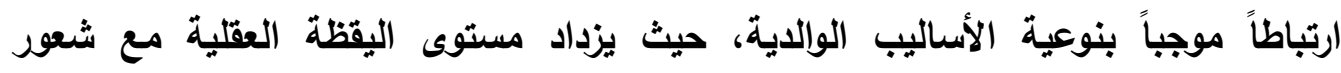

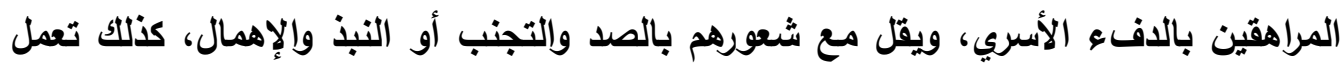
اليقظة العقلية على تخفيف حدة حالة القلق النفسي الناجمة عن أساليب الرعاية الوالدية

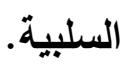
كما أجرى خضر ياسين وآمال عليوي (10 ب ب) دراسة هافت إلى تناول العلاقة بين

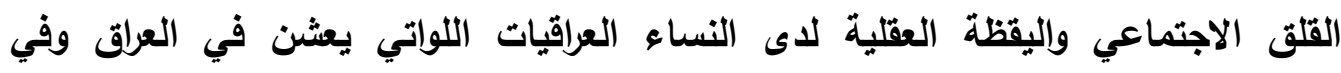

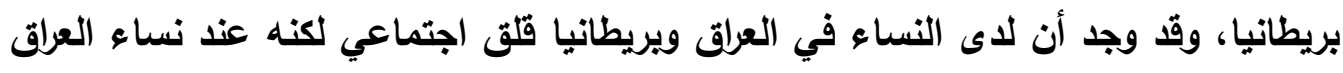

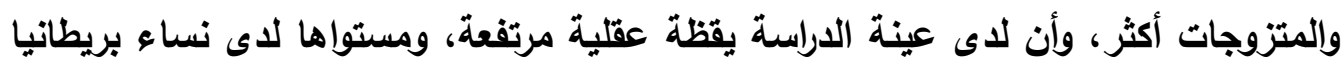
أكثر ، وأن العلاقة بين القلق الاجتماعي واليقظة العقلية هي علاقة ضعيفة. 
أما دراسة العاسمي (10 ب) فقد هدفت إلى اكتثاف دور اليقظة العقلية كوسيط للعلاقة بين المرونة النفسية وكل من الاكتئاب والضغوط النفسية لاى طلاب كلية التربية

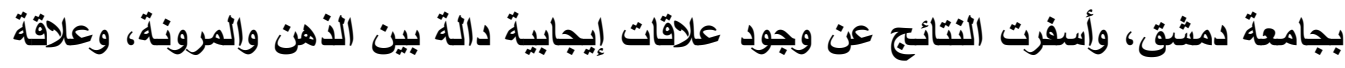
سلبية بين اليقظة العقلية وكل من الاكتئاب والضغوط، كما أظهرت النتائج أن الطلبة الذين يتسمون باليقظة العقلية أكثر مرونة وأقل اكتئاباً وضغوطاً من الطلبة منذفضي اليقظة

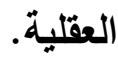

كما أجرى سانكيثا (Sangeetha, 2014) دراسة تهذف هذه الدراسة إلى اختبار أثر ممارسة اليقظة العقلية كعامل مسهم في تخفيف حدة الضغوط ورفع مستوى التحصيل الاكاديمي لاى طلبة الصف السابع، وقد توصلت الدراسة إلى وجود تأثير وسيط لليقظة العقلية في العلاقة بين التعرض للضغوط وما ينتج عنها من إجهاد وتوتر، كما أظهرت النتائج

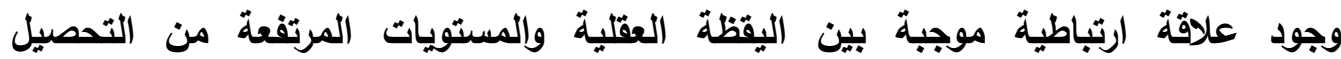

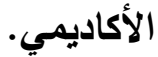

فيما هدفت دراسة أحلام عبد الله (r ب r) إلى التعرف على مستوى اليقظة الذهنية

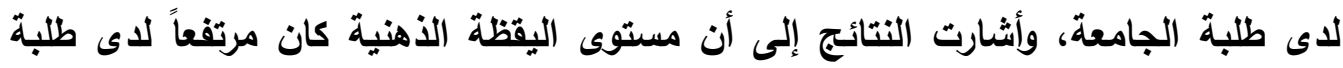

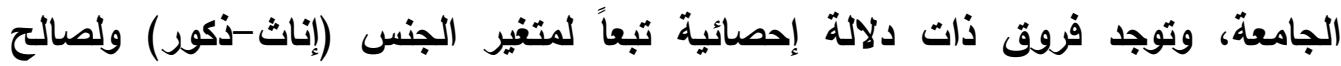
الذكور، ولا توجد فروق دالة إحصائياً تبعاً لمتغير التخصص (علمي-أدبي)، وتوجد فروق التهات

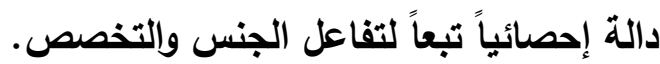

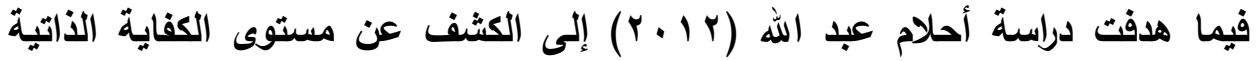
الدركة وعلاقتها باليقظة الذهنية والوظائف المعرفية لدى طلبة جامعة ديالى وقد أسفرت نتائج الدراسة عن وجود مستوى مرتفع لدى أفراد عينة الدراسة من الكفاية الذاتية المدركة،

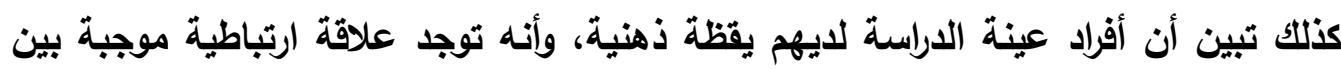
الكفاية الذاتية المدركة واليقظة العقلية. القلق Anxiety تتعدد وتنوع التعريفات التي قُمت لمفهوم القلق بشكل كبير، ويرجع ذلك إلى اهتمام

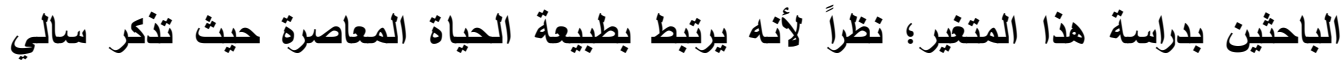

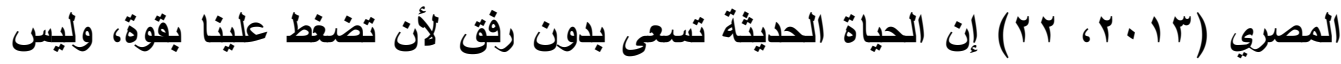


هناك من لا يشعر بالاضطراب أحياناً؛ لأنه لا يستطيع تحمل بعض أعباء حياته اليومية ومريكاتها التي تفوق قوة احتماله وطاقته، وهذا ما أدى بدوره إلى القلق.

وفي اتجاه يريط بين القلق والثعور بالتوتر يعرف بانابوتو وكاركلا وميتي

(Panayiotou, Karekla\& Mete, 2014, 316) الارتياح تحسباً لحدوث تهايد ما، وهذا التهايد به غموض أو شعور عام بعدم الراحة، بينما Niles, et al., 2015, ) في اتجاه آخر ينظر للقلق على أنه ردة فعل؛ يعرفه نيل وآخرون 110) بأنه رد فعل نفسي وجسدي نتيجة الثد العصبي ومواقف الحياة اليومية غير المريحة،

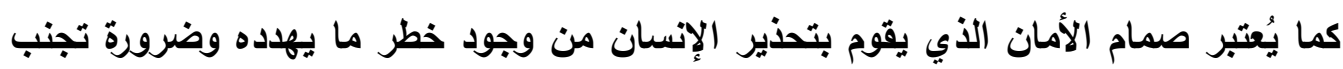

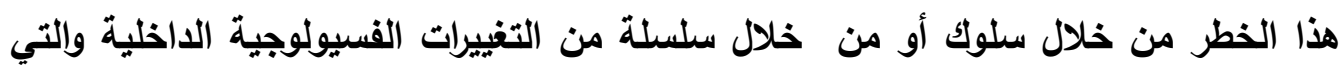
من شأنها مساعدة الإنسان على التعامل مع موقف الخطر الوشيك سواء بالهرب من الموقف

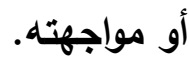

(Drake, يما وجد اتجاه يعرف القلق بأنه اضطراب انفعالي، ومن ذللك تعريف دراكئ

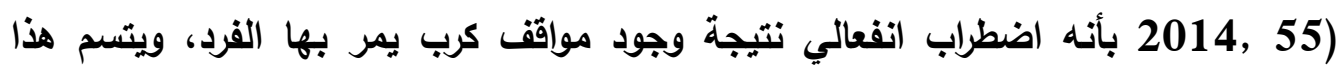
الاضطراب بمشاعر التوتر والتهيب والعصبية والانزعاج، وتُعايش هذه الحالات الانفعالية بواسطة الفرد عندما يمر بمواقف معينة ثثير قلقه.

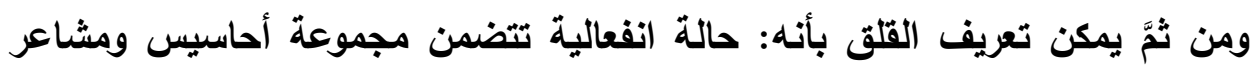

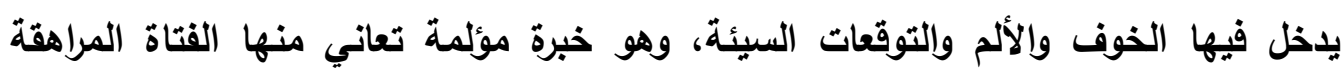

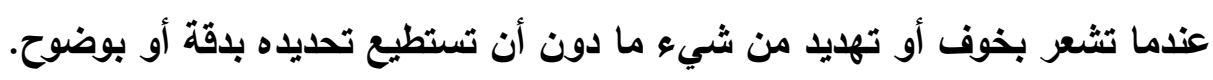

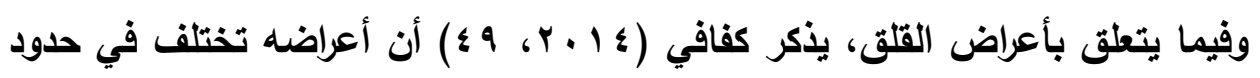

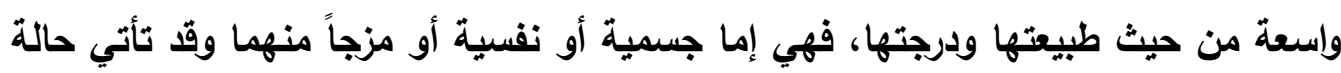

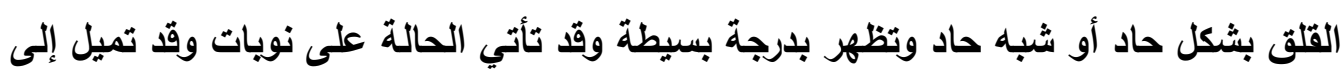
ان تكون مزمنة وليس هناك حـ لإمكانية ظهور الأعراض المرضية من نفسية أو جسمية.

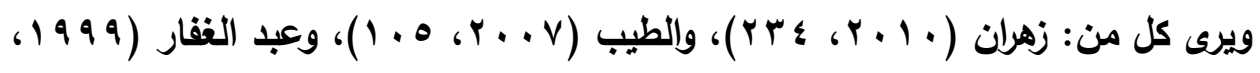

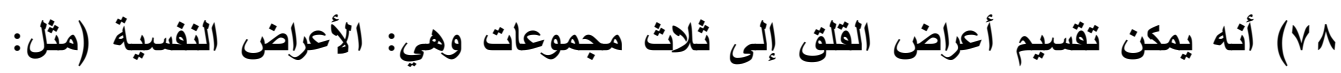
القلق على المستقبل وعلى الصحة والعمل، والحساسية النفسية الزائدة)، والأعراض الجسمية 
(مثل: الضعف العام ونقص الطاقة الحيوية، والتعب والصداع المستمر وتصبب العرق)، والأعراض النفس جسمية (مثل: البول السكري، وقرحة المعدة، والقولون العصبي).

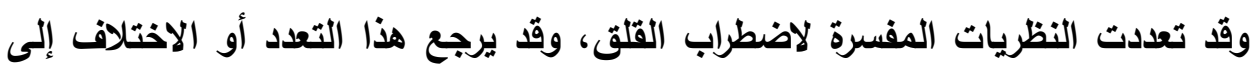

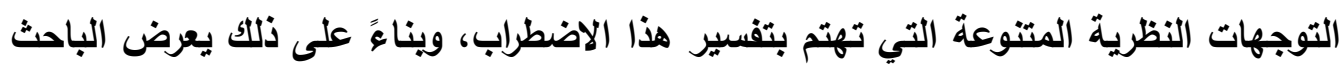
هذه النظريات المتنوعة التي اهتمت بتفسير السلوك المضطرب المني ومنها: Michail\& Birchwood, 2014, ) نظرية التحليل النفسي: يذكر ميشل ويريتشوود 103) أن فرويد (Freud) يرى أن القلق هو المشكلة المركزية في العصاب، وقد عرفه

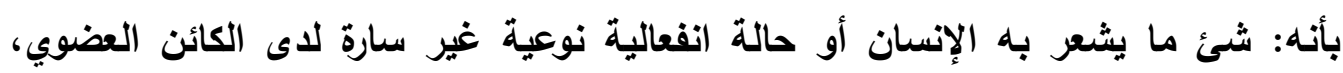
ويتضمن مكونات ذاتية فسيولوجية وسلوكية، ويُعد فرويد من أول من منح القلق الدور الحاسم في كل من نظرية الثخصية وفي دراسة أسباب الاضطرابات النفسية والنفسجسمية،

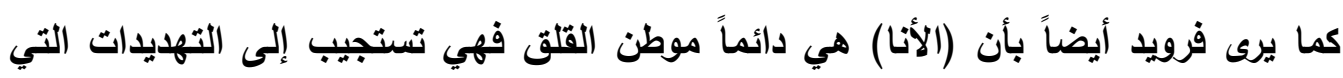

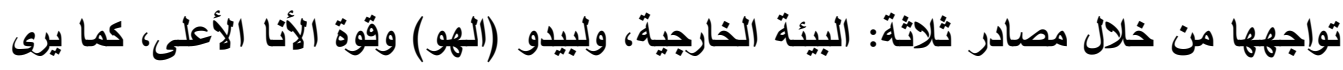
ان القليل من القلق مطلوب لإعادة التوازن النفسي.

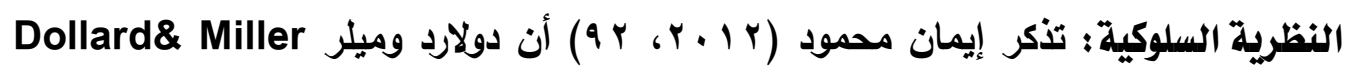

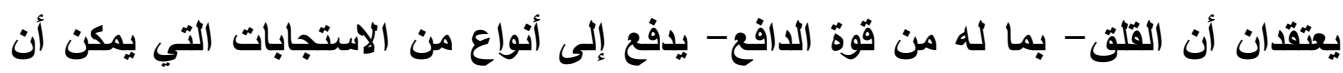
تخفف من حدته، حيث يلجأ الفرد القلق إلى بعض الممارسات مثل الحيل الدفاعية كالتبرير

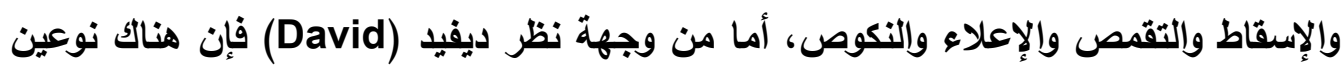

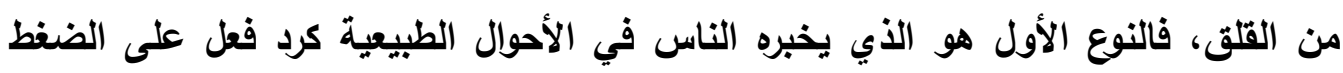

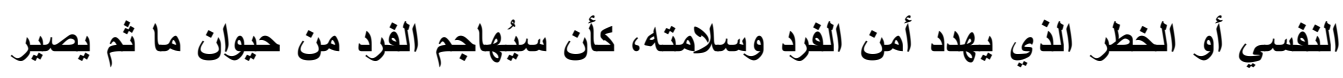

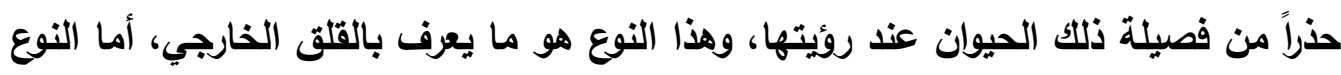
الثاني فهو داخلي المنشأ، وهو يعني أن المشكلة الرئيسية تنبع من مصدر مان ماندان داخل كيان الفرد، أي أن هناك استعداداً وراثياً لمثل هذه لهي النويات من القلق دونما سبب ظاهر .

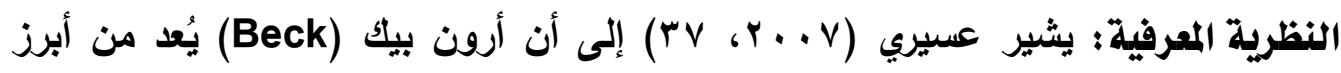

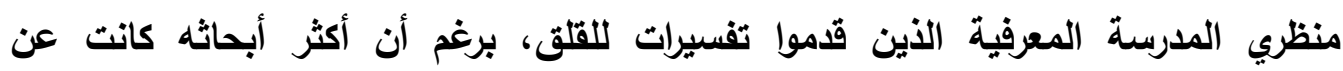
الاكتئاب، إلا أنه طبق مفاهيمه المعرفية عن الأفكار التلقائية والتعريفات المعرفية برتية والتخطيطات المعرفية في تفسير الاضطرابات الانفعالية الأخرى ومنها القلى، ويرى بيك أن الن 
الاضطرابات الانفعالية تكون ناتجة أساساً عن اضطرابات في تفكير الفرد فطريقة تفكير الفرد وما يعتقده وكيف يفسر الأحداث من حوله كلها عوامل هامة في الاضطراب الانفعالي، لذابـ الذابه يؤكد بيك في أعماله على أن توقع الفرج للأخطار والثرور هي المكونات الأساسية التي تميز

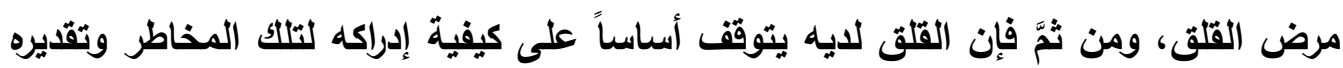

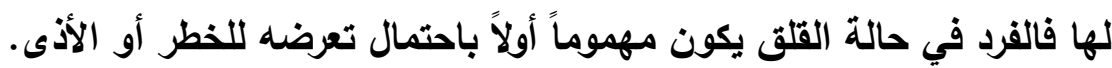

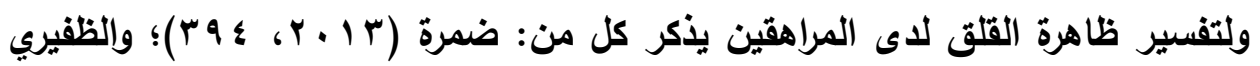

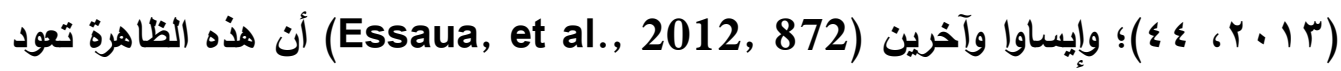
إلى العديد من العوامل، ومنها أن هناك قدرات معرفية معينة تُعد ضرورية من أجل دعم

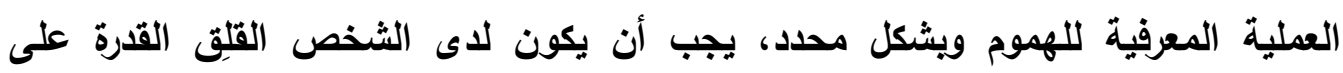

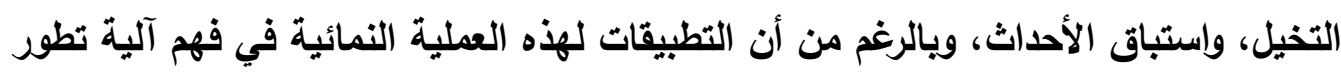

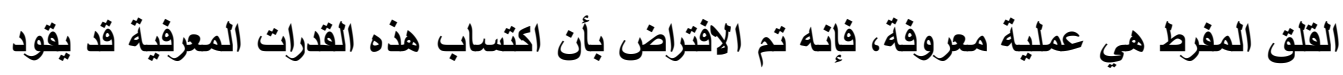
بعض المراهقين إلى زيادة تعميم القلق، كما تُعد مرحلة المراهقة مرحلة مليئة بالتغيرات في الحياة، الأمر الذي يستثير القلق لايه في هذه الفترة، فبالرغم من أن مرحلة المراهقة

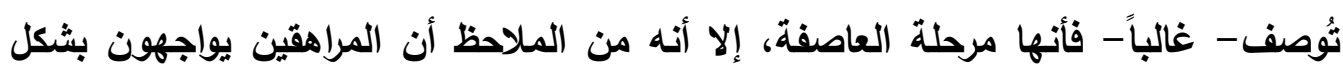

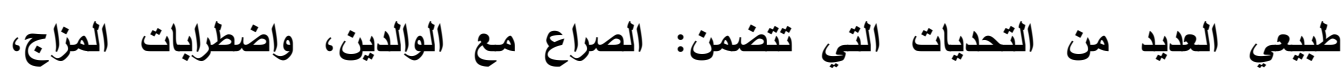

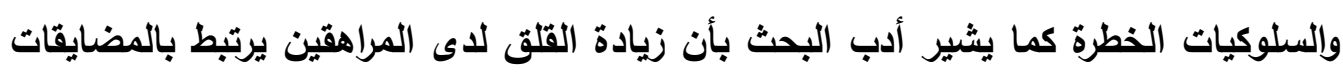

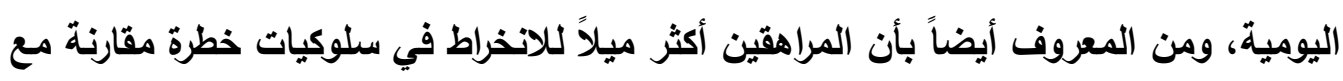
الأطفال الأصغر سناً، أو الراشدين، ومع تكرار هذه النتائج فقد يكون ذلك سبباً في زيادة القلق.

ومن الدراسات التي اهتمت بتتاول أعراض القلق في علاقتها ببعض المتغيرات دراسة

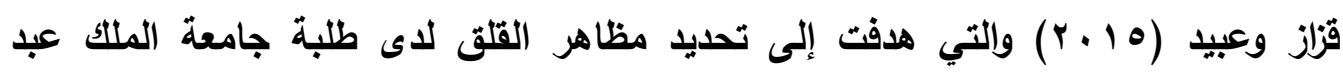

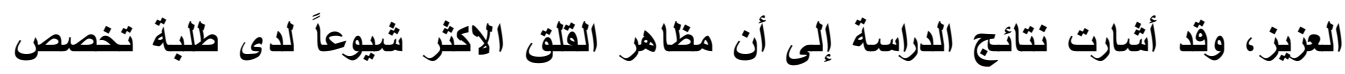

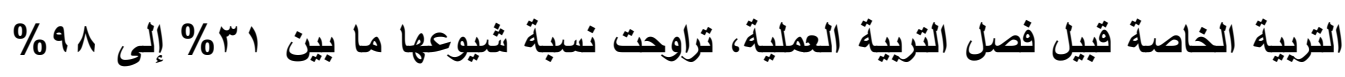
جاء على رأسها كل من الشعور بالقلق من وجود مواد متبقية ترافق مع الفصل الميداني

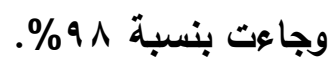




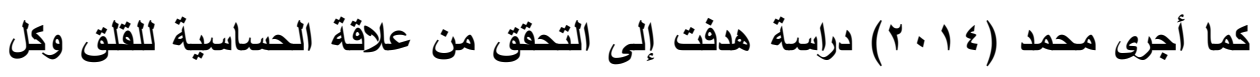

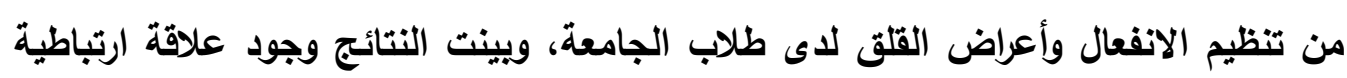

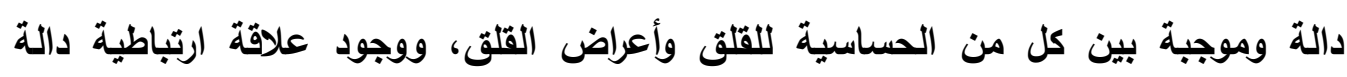

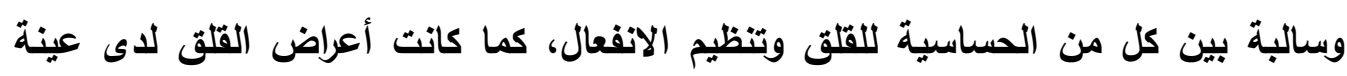
الدراسة مرتفعة.

فيما هدفت دراسة أوشيدا (Uchida, 2014) إلى دراسة السلوك العدواني في علاقته

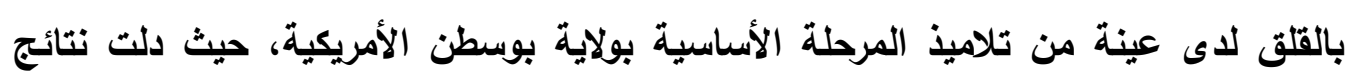

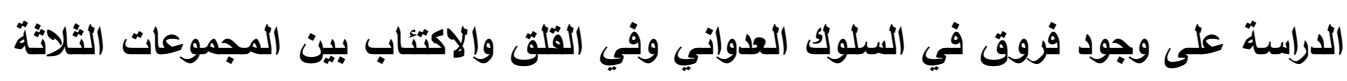

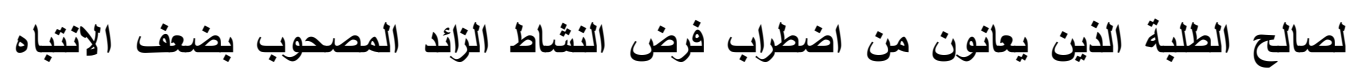

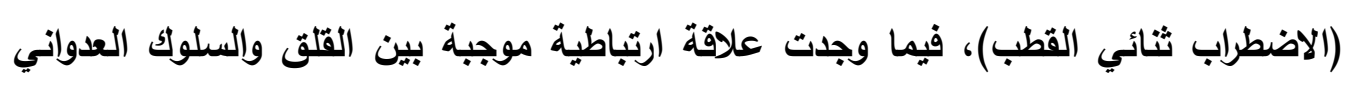

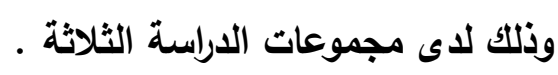
أما دراسة لاكنر ومارشال وسانتيسو وديوان ووادي وسجالووتز Marshall, Santesso, Dywan, Wade\& Segalowitz, 2014) التحقق من إمكانية التتبؤ بالسلوك العدواني من مستوى القلق لدى عينة من الطلبة

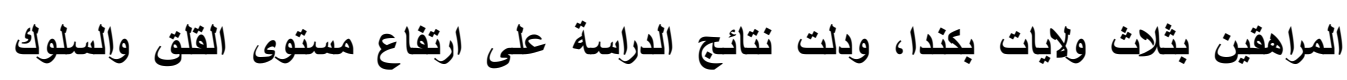

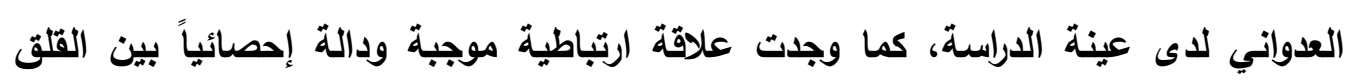
والسلوك العدواني.

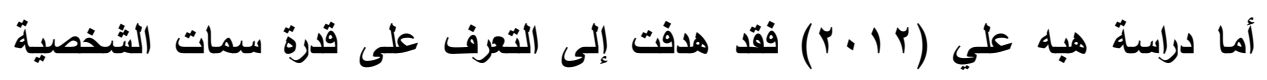

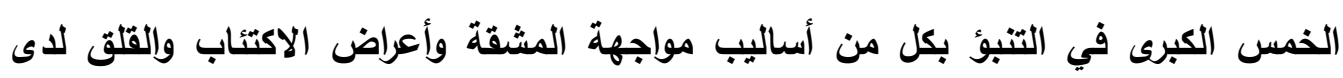

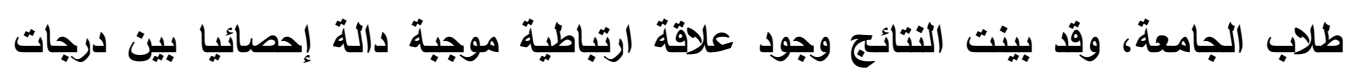

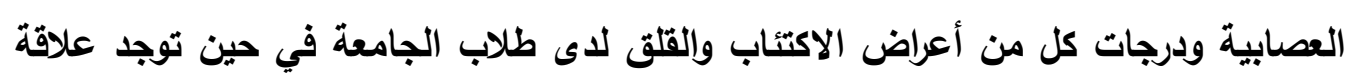

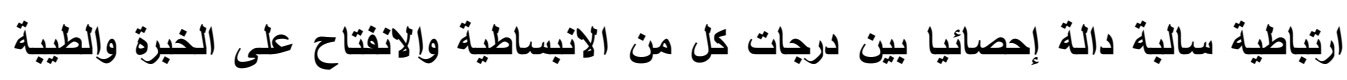

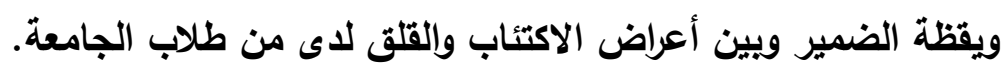

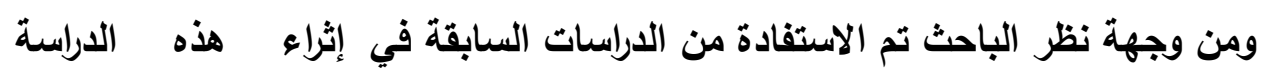
بالمراجع التي استخدمت في الإطار النظري، والمنهج الذي تم إتباعه، وإجراءات الداراسة، 


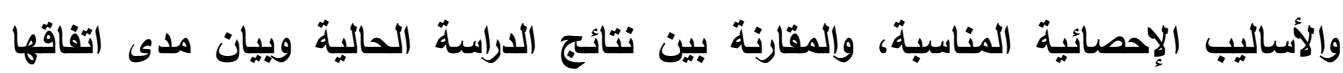
وتعارضها مع نتائج الدراسات السابقة.

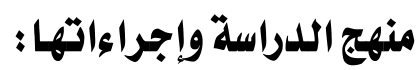

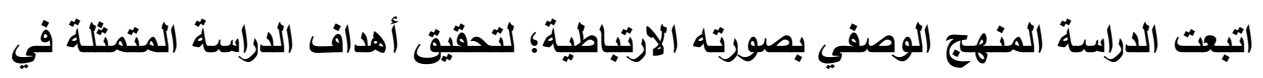
تصديد درجة كل من اليقظة العقلية وأعراض القلق والعلاقة بينهما لاى طلاب الكلية التقبية

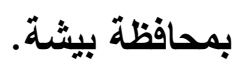

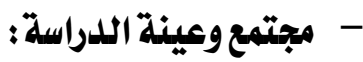

تكون مجتمع الدراسة من جميع المتدربين (مسمى الطالب بالكلية التقتية "متدرب")

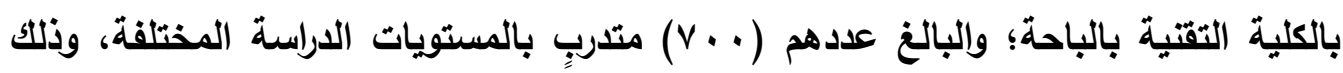

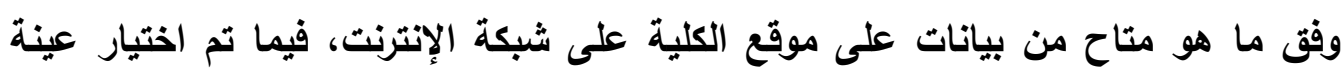

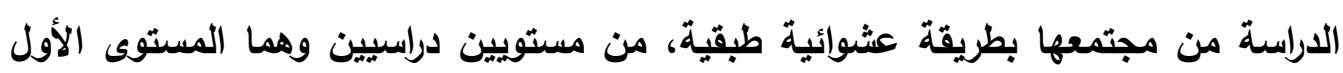

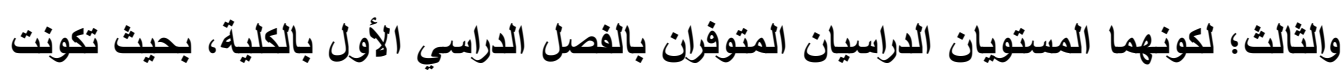
العينة في صورتها النهائية من (ع ب^) متدرياً.

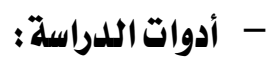

اعتمدت الدراسة الحالية على استخدام مقياسين: الأول؛ مقياس اليقظة العقلية (تقتين:

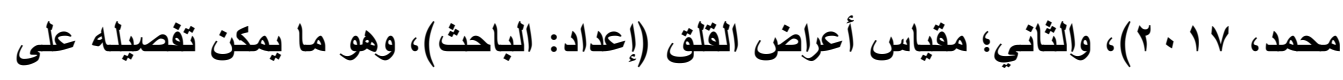
النحو التالي: - (الني أولاً: مقياس اليقظة العقلية: الئي أعد هذا المقياس في صورته الأصلية كل من جونسون وبيرك ويرينكمان وواد (Johnson, Burke, Brinkman\& Wade, 2016) اليقظة العقلية لاى المراهقين The Comprehensive Inventory of Mindfulness Experiences-Adolescents (CHIME-A العربية، يتكون المقياس في صورته التي تم تطبيقها على عينة من طلبة المرحلة الثانوية

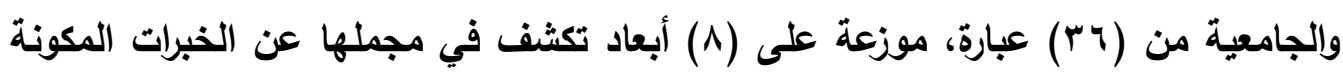

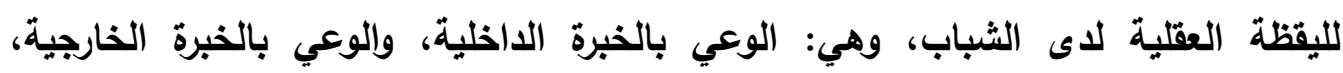

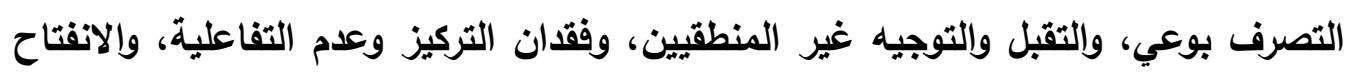


على الخبرات، ونسبية الأفكار، والفهم الواعي (البصيرة)، وقد بناء بدائل الاستجابة على الفقرة

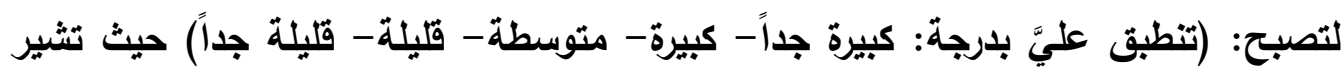
الارجة المرتفعة إلى وجود مستوى مرتفع من اليقظة العقلية.

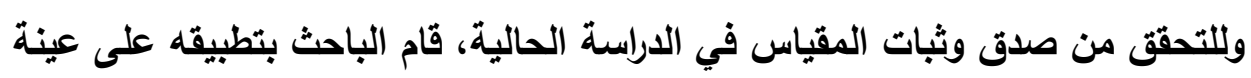

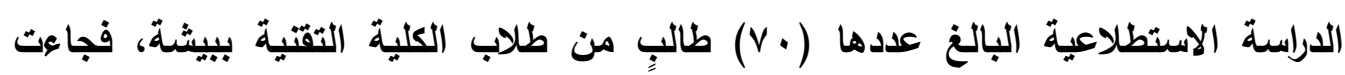

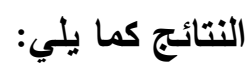

(1) الصدق: قام الباحث بحساب صدق المقياس باستخدام طريقة الاتساق الاخلي؛ والتي تعتمد على حساب معامل الارتباط البسيط لبيرسون وفق المراحل الثلاث التالية:

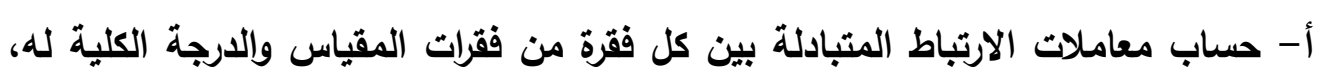

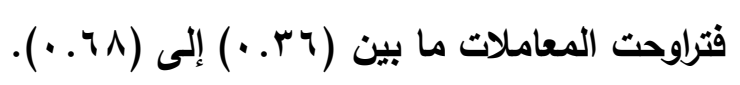

ب- حساب معاملات الارتباط المتبادلة بين كل فقرة من فقرات المقياس، والدارجة الكلية

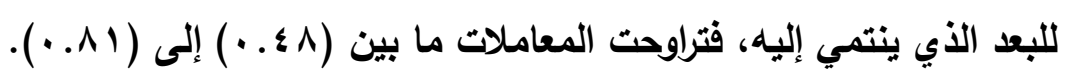

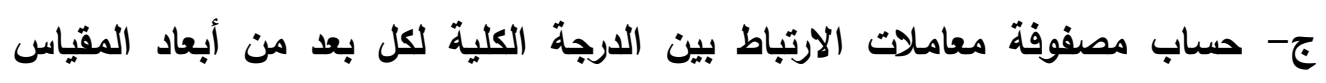

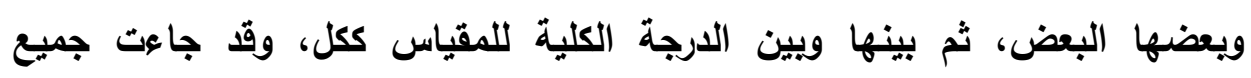

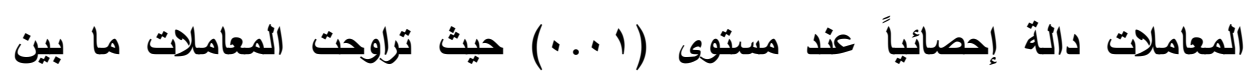

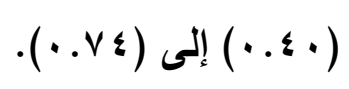

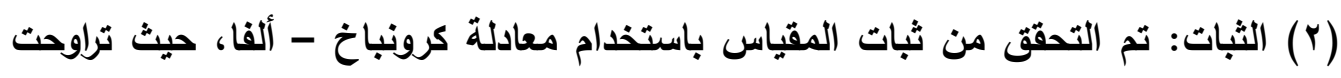

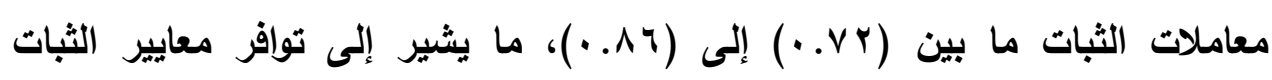
للمقياس، ويدفع نحو الثقة في استخدامه عبر الدراسة الحالية. ثانياً : مقياس أعراض القلق. أعد الباحث مقياساً لأعراض القلق لدى الثباب، وقد مر إعداد المقياس بالخطوات التالية: - تحديد الهذف من المقياس: وتمثل في الكثف عن أعراض القلى كحالة لاى طلاب الكلية التقنية. - تحديد مصادر اشتقاق عبارات المقياس: وذلك من خلال قيام الباحث بمراجعة نوعين من

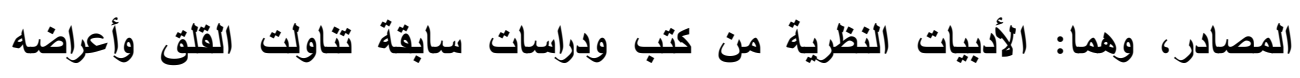

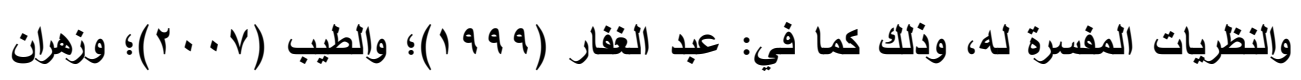




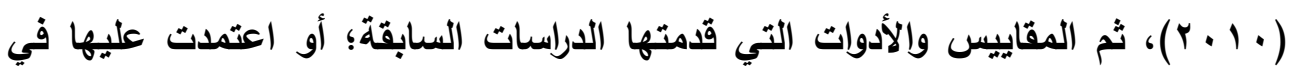

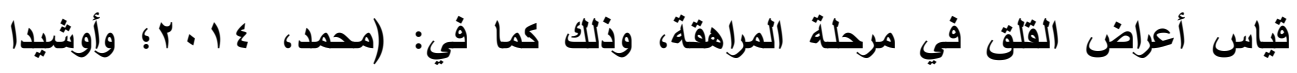
Uchida, et al., 2014

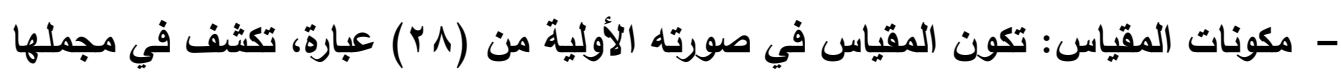

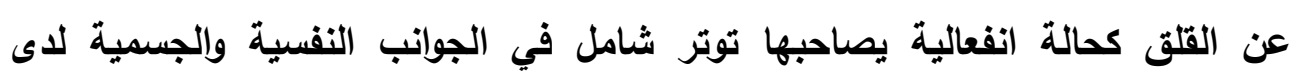

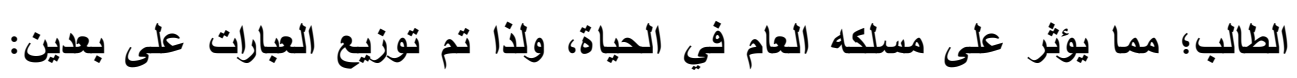

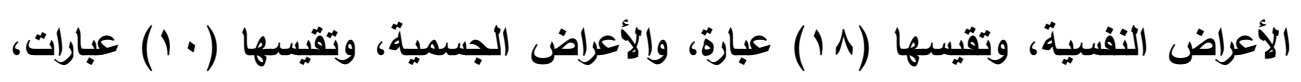

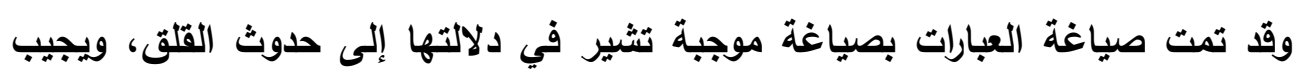

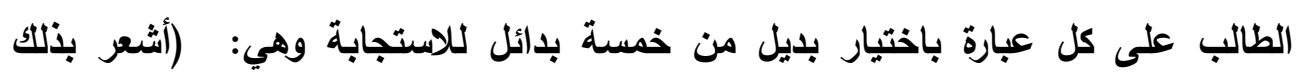

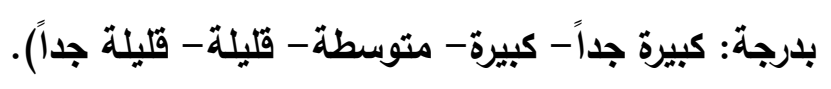

- التحقق من صدق المقياس وثباته: وذلك من خلال الخطوات الإجرائية التالية:

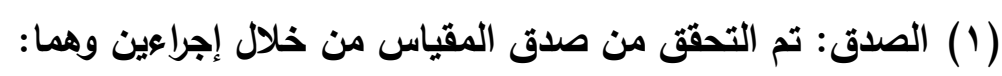

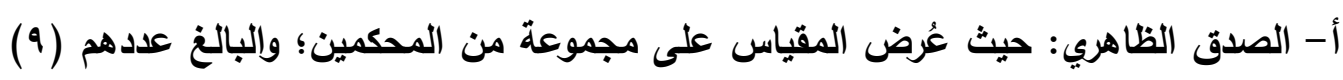

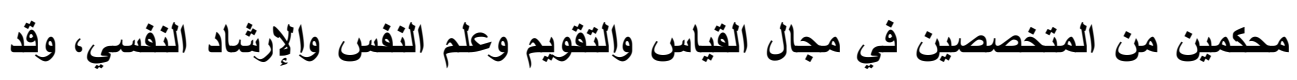

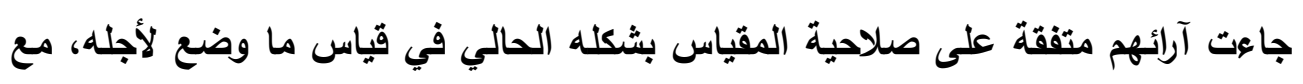

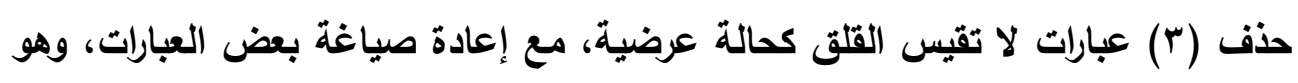

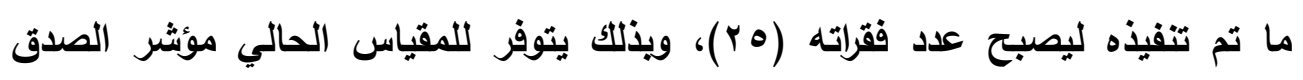
الظاهري.

ب- صدق الاتساق الداخلي: والذي تم حسابه وفق المراحل الثثلاث التالية:

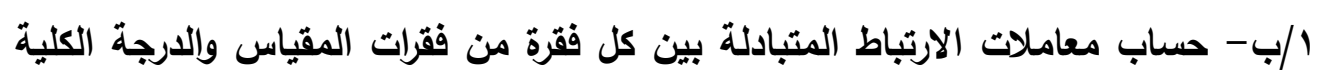

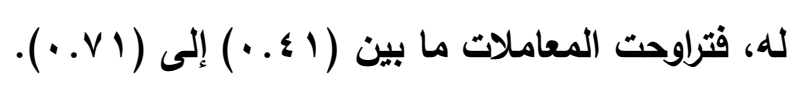

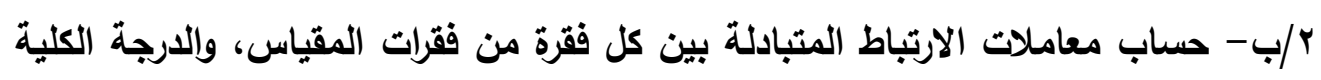

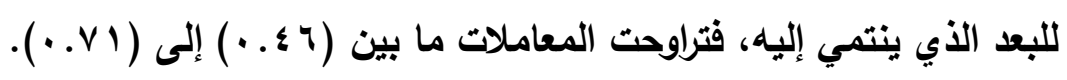

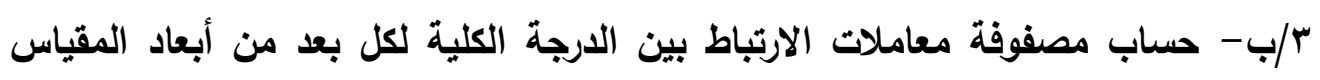

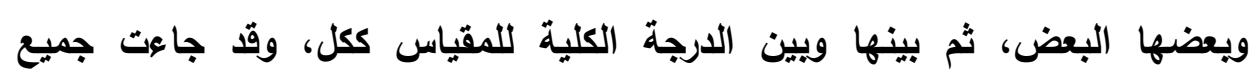




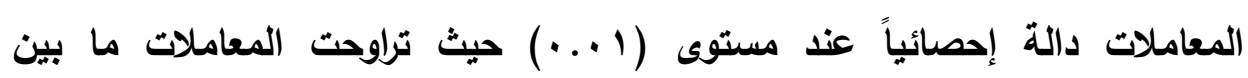

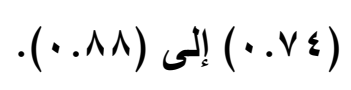

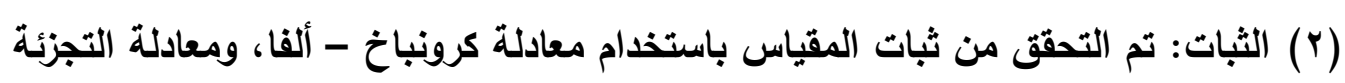

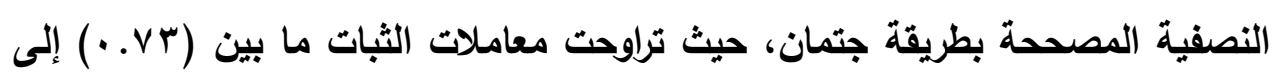

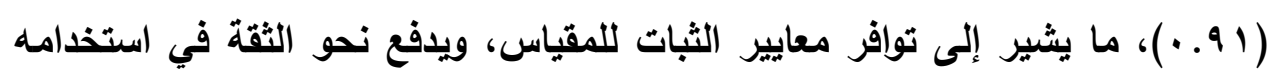
عبر الدراسة الحالية.

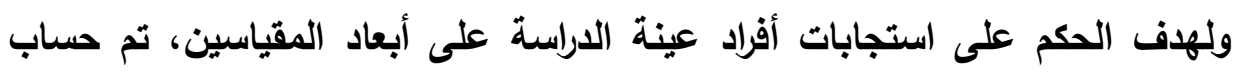

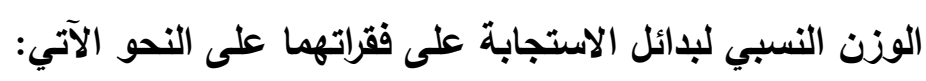

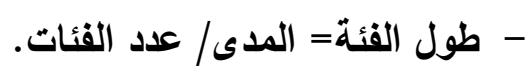
- العدى= الفرق بين أكبر وأصغر بديل (درجة بديل الاستجابة) / عدد بدائل الاستجابة.

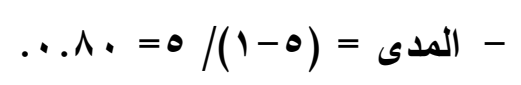

ويالتالي يكون مقياس الحكم على درجة التوفر على النحو الآتي:

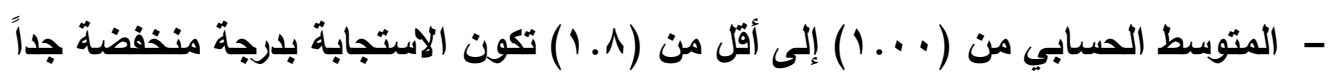

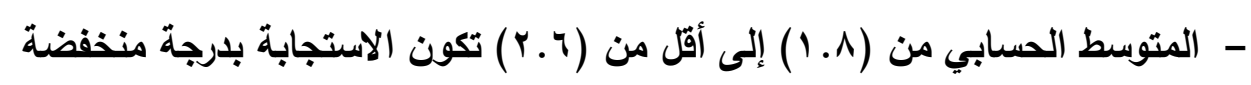

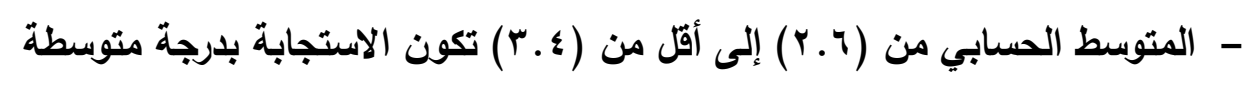

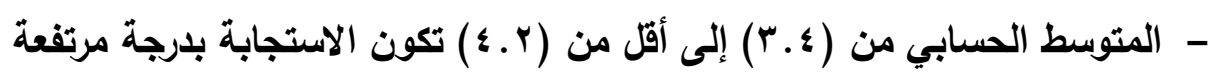

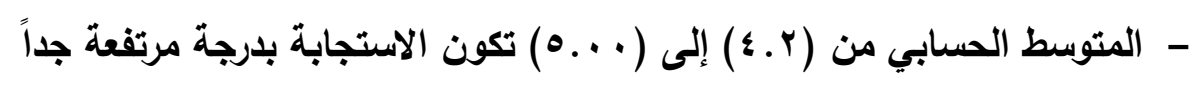
نتائج الدراسة ومناقشتها وتفسيرها: النتائج التتعلقة بالسؤال الأول: ونصه: ما دلالة العلاقة الارتباطية بين ما العلاقة بين اليقظة العقلية وأعراض القلق

$$
\text { لاى طلاب الكلية التقتية بمحافظة بيثة؟ الافية }
$$

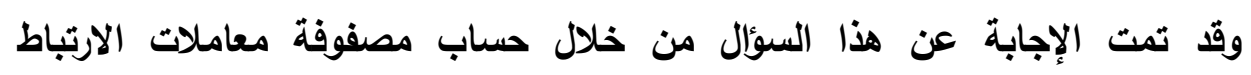

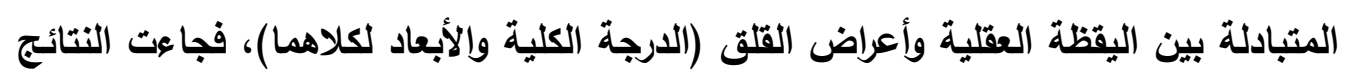

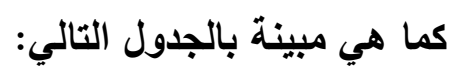


اليقظة العقلية وعلاقتها بأعراض القلق لدى طلاب الكلية التقنية بمحافظة بيشة.

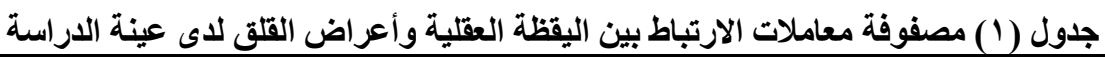

\begin{tabular}{|c|c|c|c|c|c|c|c|c|c|}
\hline \multirow[b]{2}{*}{ اللإجلية العلة } & \multicolumn{8}{|c|}{ اليقظة العقلية } & \multirow[b]{2}{*}{ المتغير } \\
\hline & الواعي & نسبية & الانفتاح & التقانيز & التيل غالتوجيل & التصرفي & الخارجيرة & الألخبر & \\
\hline $\begin{array}{c}* * . \Gamma \varepsilon \\
-\end{array}$ & $-* .1 \leq$ & $-\cdot .9$ & $\begin{array}{c}* * \cdot r \leq \\
-\end{array}$ & **. I I & $* . .1 \leq$ & $\begin{array}{c}* * . r . \\
-\end{array}$ & $\begin{array}{c}* *, \quad Y \varepsilon \\
-\end{array}$ & $-\cdot v$ & الألفسية اض \\
\hline $\begin{array}{c}* *, Y \uparrow \\
-\end{array}$ & $\begin{array}{c}* * .19 \\
-\end{array}$ &.- .11 & $\begin{array}{c}* * \cdot r q \\
-\end{array}$ & $* * ., Y \tau$ & .11 & $\begin{array}{c}* * . Y Y \\
-\end{array}$ & $-* .17$ & $\begin{array}{l}.11 \\
-*\end{array}$ & الأعسمراض \\
\hline $\begin{array}{c}* * . . \leqslant Y \\
-\end{array}$ & $\begin{array}{c}* . Y 1 \\
-*\end{array}$ & $\begin{array}{c}* .14 \\
-\end{array}$ & $\begin{array}{c}* . Y Y \\
-*\end{array}$ & $\begin{array}{c}* .{ }^{*} \\
*\end{array}$ & $* . .1 \mathrm{~V}$ & $\begin{array}{c}* * .11 \\
-\end{array}$ & $\begin{array}{c}* . . Y V \\
-*\end{array}$ & $\begin{array}{l}.10 \\
-*\end{array}$ & لألعراضلة الألة \\
\hline
\end{tabular}

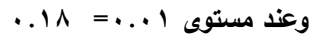

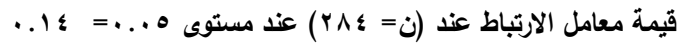

يتبين من الجدول (1) على مستوى الارجات الكلية، إن الدرجة الكلية لليقظة العقلية

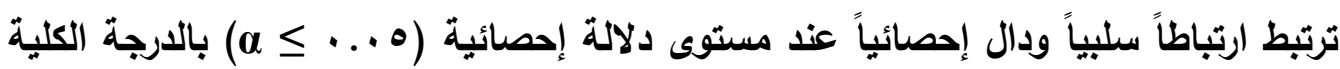

للقلق والأبعاد الفرعية له، أما على مستوى أبعاد اليقظة العقلية فقد جاعت المعاملات:

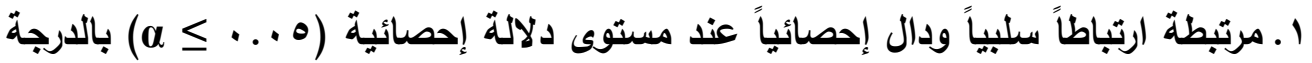
الكلية للقلق، وذلك في أبعاد: الوعي بالخبرة الاخلية، والوعي بالخبرة الخارجية، والتصرف بوعي، والانفتاح على الخبرات، ونسبية الأفكار، والفهم الواعي.

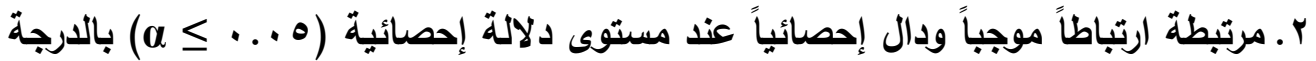
الكلية للقلق، وذلك في بعدي: التقبل والتوجيه غير المنطقيين، وفقدان التركيز وعدم التفاعلية.

وتبين التتيجة الحالية في مجملها وجود علاقة عكسية بين اليقظة العقلية وأعراض القلق، فكلما ارتفعت درجة اليقظة العقلية كلما قلت أعراض القلق شدة وتكراراً، وهو بدوره ما يشير إلى إمكانية ان تعمل اليقظة العقلية على التخفيف من حدة أعراض القلق لاى طلاب الكلية التقتية.

ويمكن تفسير النتيجة الحالية في ضوء أدبيات الدراسة التي تبين أن توظيف اليقظة

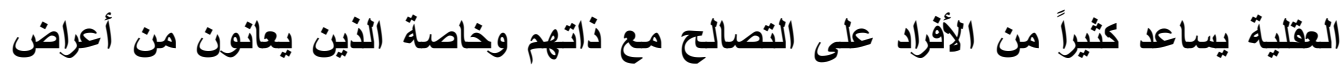
القلق والاكتئاب (Grow, Collins, Harrop\& Marlatt, 2015, 17)، كما يذكر 
ويتكويتس ويوين ودوغلاس وهسو ,Witkiewitz, Bowen, Douglas\& Hsu, 2013) (1564 إلى أن اليقظة العقلية تعمل كمتغير واقٍ من العودة الى الأمراض النفسية، إذ تعمل على التخفيف من حدة الأعراض المرضية. يعزو الباحث النتيجة الحالية أن اليقظة العقلية تعمل على تجنيب الفرد إصدار الأحكام السلبية على ذاته، وهو ما ينعكس إيجاباً على مستوى الشعور بالقلق والتوتر؛ والذي تقل

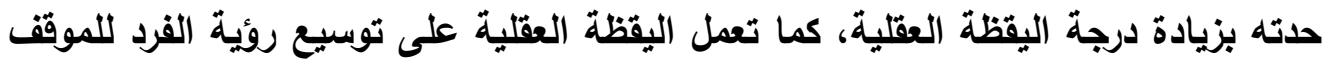
الأي يمر به، فيزداد إدراكاً له، ويالتالي تخف عنده حدة القلق المصاحبة لهذا الموقف وما قد تحمله من أعراض للقلق لايه، كما أن وجود درجة مناسبة من اليقظة العقلية لاى لهي الطالب، تعمل على زيادة وعيه وتركيزه العقلي على تأثير الخبرات التي يمر بها على جسده وعلى مشاعره الداخلية، ويالتالي يمكنه التحكم فيها، فتخف حدة أعراض القلق وفقاً لذلك. وإجمالاً، يرى الباحث أن النتيجة الحالية تمثل منطلقاً لتحديد مدى مسؤولية اليقظة العقلية للتخفيف من حدة أعراض القلق لدى طلاب الكلية التقنية بمحافظة بيشة، وذلك وفق مأق ما تكشف عنه نتائج الإجابة عن الأسئلة التالية التي قدمتها الدراسة. نتيجة الإجابة عن السؤال الثاني:

ونصه: ما درجة اليقظة العقلية لاى طلاب كلية التقنية بمحافظة بيشة ؟ تمت الإجابة عن هذا السؤال من خلال حساب المتوسطات والاتحراقات المعيارية لمقياس القياس العقلية وأبعاده، فجاءت النتائج كما هي مبينة بالجدول التباتية التالي:

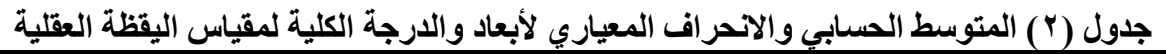

\begin{tabular}{|c|c|c|c|c|c|}
\hline درجة التوفر & الالاحعرافي & $\begin{array}{c}\text { الحسابي (م) } \\
\text { (المتوسط }\end{array}$ & 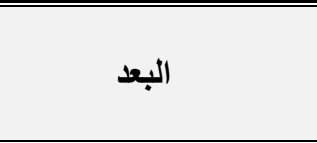 & الترتيب & البعد \\
\hline مرتفعة & 1.14 & 3.67 & الوعي بالخبرة الخارجية & 1 & r \\
\hline مرتفعة & 0.97 & 3.61 & الوعي بالخبرة الداخلية & r & 1 \\
\hline متوسطة & 0.70 & 3.56 & التقبلَ والتوجيه غير & $r$ & $\varepsilon$ \\
\hline متوسطة & 1.03 & 3.18 & الانفتاح على الخبرات & $\varepsilon$ & 9 \\
\hline متوسطة & 1.04 & 3.06 & الفهم الّواعي & 0 & $\Lambda$ \\
\hline متوسطة & 0.88 & 2.95 & التصرف بوعي & 7 & $r$ \\
\hline منخفضة & 0.86 & 2.66 & فقادان التركيز وعدم & $\mathrm{v}$ & ๑ \\
\hline منخفضة & 1.19 & 2.54 & نسبية الأفكار & $\Lambda$ & 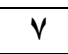 \\
\hline متوسط & 0.98 & 3.15 & ققياس اليقظة العقلية & جة الكلية & \\
\hline
\end{tabular}


يتبين من الجدول (r) أن درجة اليقظة العقلية لدى طلاب الكلية التقتية ببيشة جاعت

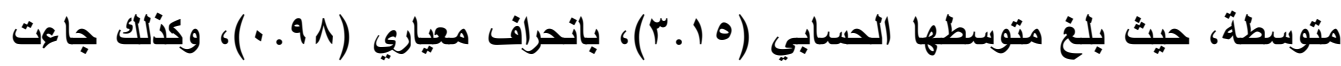

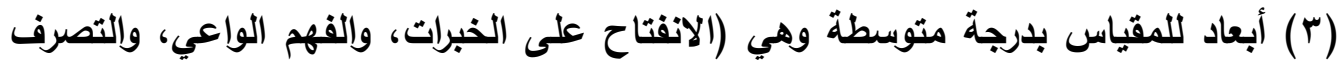
بوعي)، فيما جاعت درجة (ب) أبعاد مرتفعة وهي (الوعي بالخبرة الخارجية- الوعي بالخبرة الداخلية- التقبل والتوجيه غير المنطقيين)، بينما جاعت درجة (بعدين) منخفضة وهما (فقدان التركيز وعدم التفاعلية، ونسبية الأفكار). ويعزو الباحث التتيجة المتوسطة لليقظة العقلية لاى طلاب الكلية التقتية إلى مجموعة

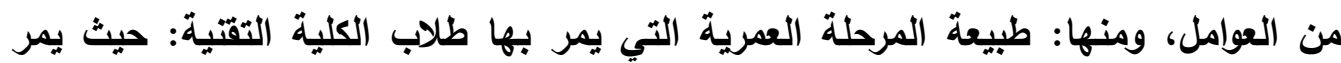
الطلاب بمرحلة المراهقة المتأخرة؛ والتي يعمد الفرد خلالها إلى تحديد هويته ونمط حياته، ويتطلع نحو الاخول إلى مرحلة الرشد، وهذا ما يدفع الفرد نحو الاستبصار بذاته ويالعالم

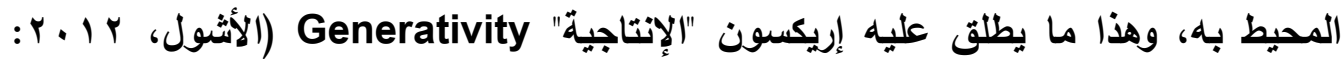

Brown\& Ryan, ) ومنها أيضاً ما تجمع عليه الأدبيات النفسية كما في بروان وريان 2003)؛ ونيف (Neff, 2003) من أن اليقظة العقلية مكون متعلم يكتسبه الفرد من خلال تفاعله مع البيئة المحيطة به وما يترتب على هذا التفاعل من نتائج، وطلاب الكلية التقنية يمكنهم تحقيق العديد من المكاسب العلمية وإلمهنية والاجتماعية من خلال دراستهم، وهو مهات الأمر الأي ينعكس على تكوين وعي متوازن لديهم وروئية واضحة لقبول ذواتهم وإنفعالاتهم. نتيجة الإجابة عن السؤال الثالث:

ونصه: ما أكثر أعراض القلق انتثاراً لاى طلاب الكلية التقتية بمحافظة بيثة؟ تمت الإجابة عن هذا السؤال من خلال حساب المتوسطات والانحرافات المعيارية لأبعاد مقياس أعراض القلق، ثم مقارنتها بمعيار الحكم على المتوسط لبيان درجة كل بعد،

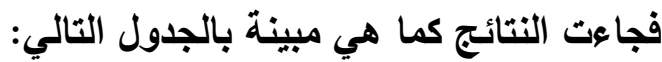
جدول (T) المتوسط الحسابي والانحر اف المعياري لأبعاد والدرجة الكلية لمقياس أعراض القلق

\begin{tabular}{|c|c|c|c|c|c|}
\hline التوففة & 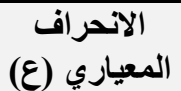 & 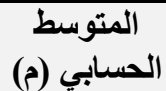 & البعد & التزتيب & رقد \\
\hline متوسطة & 0.37 & 2.84 & الأعراض النفسية & 1 & 1 \\
\hline متوسطة & 1.09 & 2.80 & الأعراض الجسمية & r & $r$ \\
\hline متوسطة & 0.73 & 3.15 & \multicolumn{3}{|c|}{ اللارجة الكلية لمقياس القلق } \\
\hline
\end{tabular}


يتبين من الجدول (r) أن درجة أعراض القلق لدى طلاب الكلية التقتية ببيشة جاعت

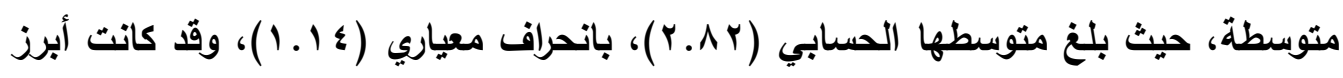

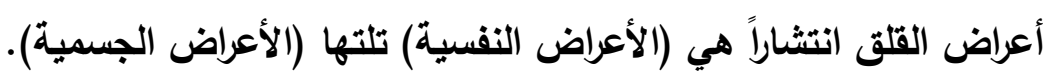

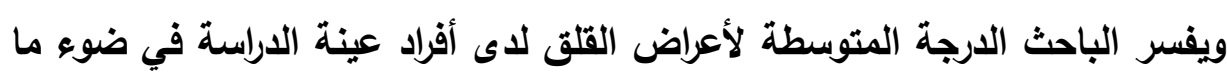

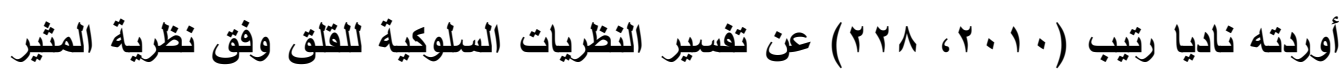
والاستجابة، بأن السلوك الذى يظهر على الكائن الحي هو نتيجة لمثير معين، وهذا ما ينطبق

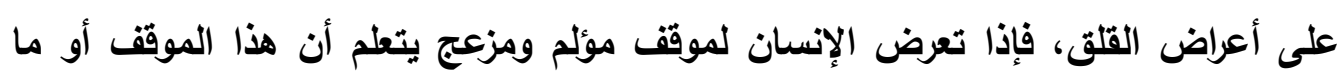

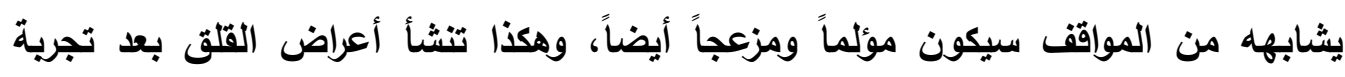

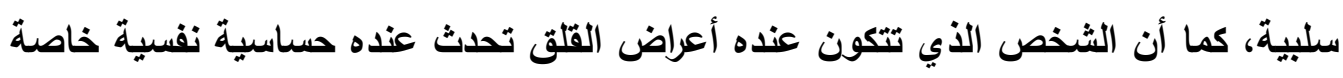

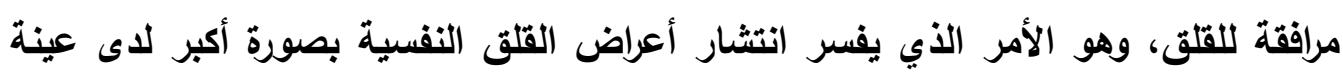
الاراسة من انتشار أعراض القلق الجسمية. كما يمكن عزو النتيجة الحالية إلى طبيعة المرحلة العمرية التي يمر بها أفراد التهاد عينة الاراسة، وهي مرحلة المراهقة؛ والتي يتأثر فيها المراهق بتقييمات الآخرين بدرجة كبيرة، وهو

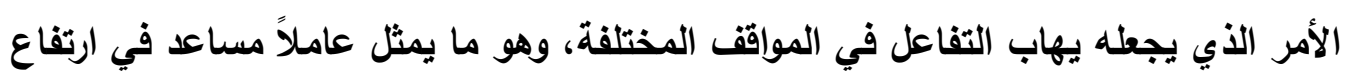

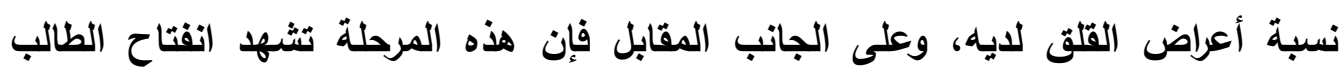

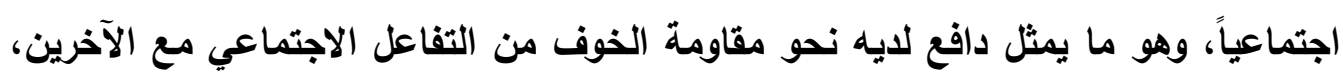

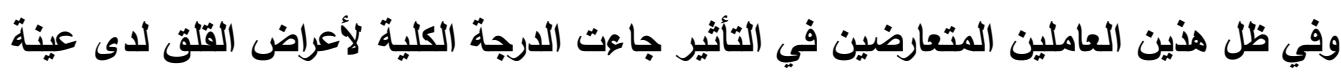
الدراسة (متوسطة) لتبدو منطقية إلى حد كبير في ضوء هذين هذين العاملين.

\section{نتيجة الإجابة عن السؤال الرابع:}

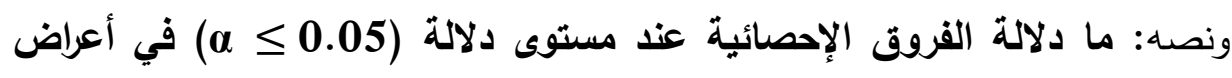
القلق لاى مرتفعي ومنخفضي اليقظة العقلية من طلاب الكلية التقتية بمحافظة بيشة؛ دلإله

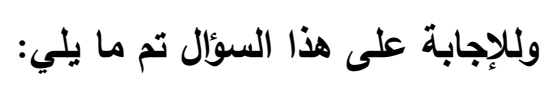

1. اختيار أعلى درجات و \% من الطلاب الذين يمثلون الإرياعي الأعلى على مقياس

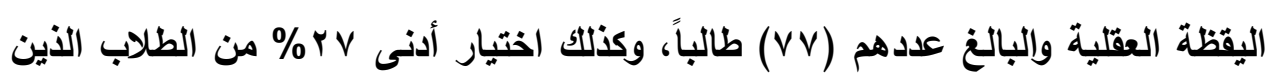
يمثلون الإرباعي الأدنى على مقياس اليقظة العقلية والبالغ عددهم (VV) طالباً. 


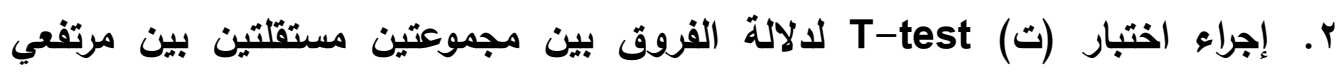
ومنذفي اليقظة العقلية على مقياس أعراض القلق، فجاءت النتائج على النحو

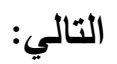

جدول (؛) نتائج اختبار (ت) لالالة الفروق بين استجابات عينة الدراسة من مرتفعي ومنخفضي

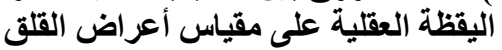

\begin{tabular}{|c|c|c|c|c|c|c|c|c|}
\hline الإلالة & قتيمة & الدرجة & المعياري & الحسابي & العدد & المجموعات & البعد & e \\
\hline \multirow[b]{2}{*}{$\because \cdot$} & \multirow[b]{2}{*}{$19 . \wedge \mu$} & \multirow[b]{2}{*}{104} & 4.46 & 43.79 & VV & مرتفعو اليقظة العقلية & \multirow[b]{2}{*}{ الأعسراضية } & \multirow[b]{2}{*}{1} \\
\hline & & & 4.59 & 58.24 & VV & منخفضو اليقظة & & \\
\hline \multirow[b]{2}{*}{$\because 1$} & \multirow[b]{2}{*}{$10 . r 4$} & \multirow[b]{2}{*}{104} & 4.01 & 18.90 & VV & مرتفعو اليقظة العقلية & \multirow{2}{*}{ الأعمراضي } & \\
\hline & & & 3.61 & 21.55 & vV & منففضو اليقظة & & $r$ \\
\hline \multirow[b]{2}{*}{$\because 1$} & \multirow[b]{2}{*}{ rA. ir } & \multirow[b]{2}{*}{ 10r } & 2.82 & 62.69 & VV & مرتفعو اليقظة العقلية & \multirow{2}{*}{\multicolumn{2}{|c|}{ لأعراض القلّق }} \\
\hline & & & 4.53 & $\mathbf{7 9 . 7 9}$ & VV & منففضو اليقظة & & \\
\hline
\end{tabular}

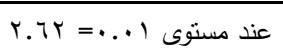

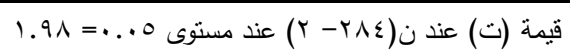

يظهر من الجدول (ع) دلالة الفروق الإحصائية بين مرتفعي ومنذفضي اليقظة

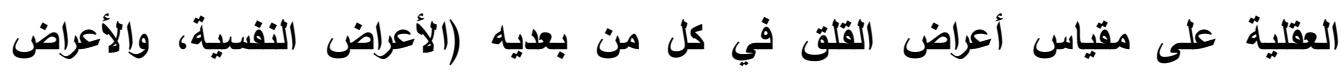

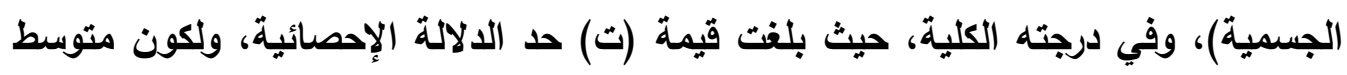

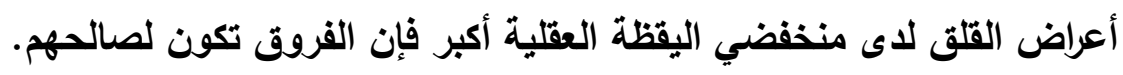

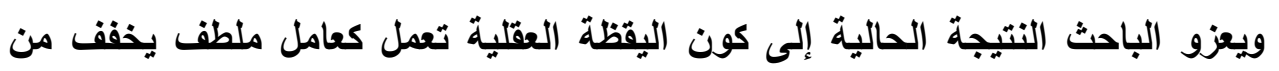

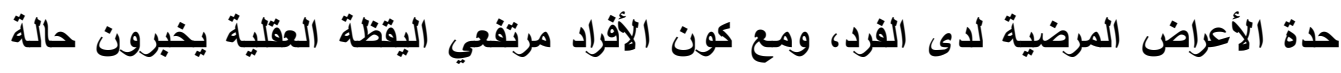

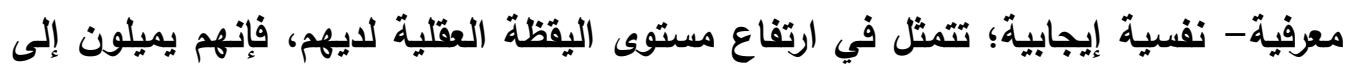

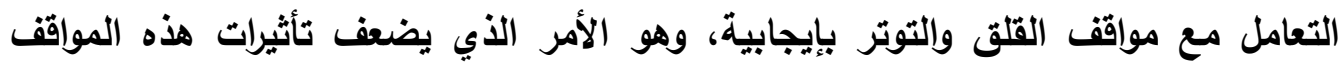

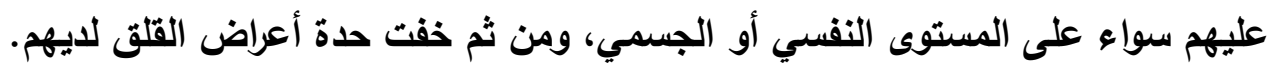
أما الأفراد منذفضي اليقظة العقلية فإنهم يخبرون حالة معرفية- نفسية سلبية، تتحدد

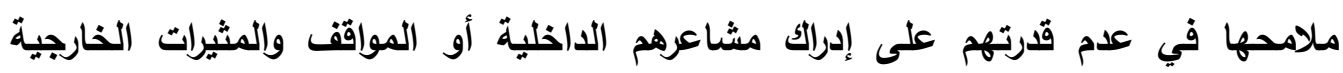

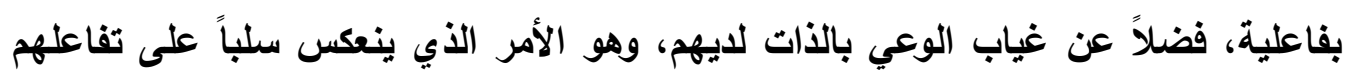
مع المواقف التي تحمل في جوانبها مشاعر القلق والتوتر. 


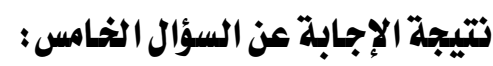
ونصه: هل يمكن التتبؤ بأعراض القلق لاى طلاب الكلية التقتية بمحافظة بيشة من

خلال درجة اليقظة العقلية لايهر؟ وللإجابة على هذا السؤال تم حساب معامل الانحار المتعدد لحساب نسبة إسهام كل

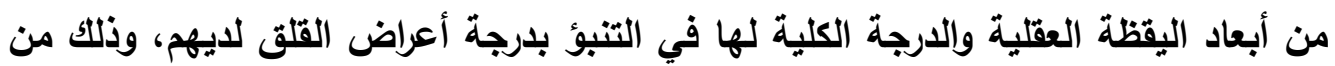

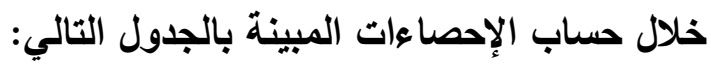
جدول (0) أثر المتغيرات المستقلة (الدرجة الكلية لليقظة العقلية وأبعادها) على المتغير التابع (أعراض القلق) (القئة

\begin{tabular}{|c|c|c|c|c|}
\hline $\begin{array}{l}* \text { *Sig. } \\
\text { (الدلادة) }\end{array}$ & $\begin{array}{c}\text { Beta } \\
\text { (قوة التأثير) }\end{array}$ & (التباين) & $\begin{array}{c}\mathbf{R}^{2} \\
\text { (معامليد) }\end{array}$ & النموذج \\
\hline$\because \cdot 1$ & 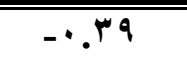 & $0 .+1$ & $9.1 \%$ & الوعي بالخبرة الداخلية \\
\hline$\because \cdot 1$ & $-\because . r \cdot$ & $\varepsilon . Y_{1}$ &. .11 & الوعي بالخبرة الخارجية \\
\hline$\because \cdot 1$ & $-\cdot . \leqslant 1$ & 7.00 & 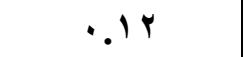 & التصرف بوعي \\
\hline$\because \cdot 1$ &. .51 & $0.1 Y$ &. $.1 T$ & التقبل والتوجيه غير المنطقين \\
\hline$\because .0$ & 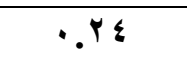 & $r . r_{1}$ & .1 & فقدان التركيز و عدم التفاعلية \\
\hline$\because \cdot 1$ & $-r . r$. & $\varepsilon . \leqslant \varepsilon$ &. $.1 Y$ & الانفتاح على الخبرات \\
\hline$\because 1$ & $-\because .9$ & $1.1 Y$ & $\because .0$ & نسبية الأفكار \\
\hline$\because .0$ & $-\because Y V$ & $r .4$ & .1 & القهم الواعي \\
\hline$\because 1$ & $\cdot .^{r q}$ & $7 . \leqslant V$ & $\because 1 \varepsilon$ & الدارجة الكلية لمقياس اليقظة \\
\hline
\end{tabular}

تبين النتائج الموضحة بالجدول (0) صلاحية نموذج تحليل الانحار في كل من أبعاد

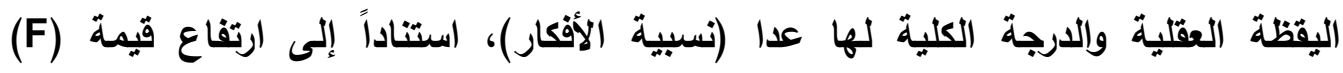

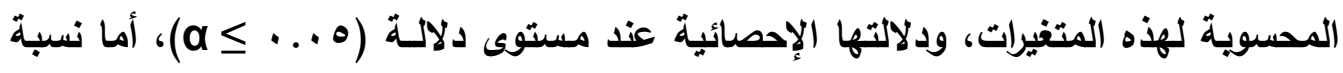

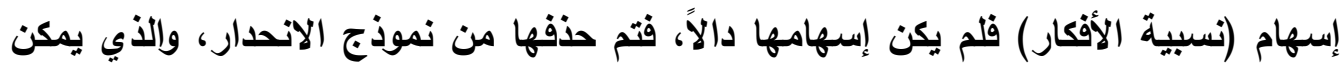
تحديد قوة الإسهام فيه على النحو الآتي:

1. الوعي بالخبرة الاخلية تفسر ب ا ا \% من درجة أعراض القلق لاى طلاب الكلية التقنية. r. التقبل والتوجيه غير المنطقيين تفسر با1\% من درجة أعراض القلق لاى طلاب الكلية التقنية.

r. التصرف بوعي تفسر r \% من درجة أعراض القلق لاى طلاب الكلية التقنية. ؛ . الانفتاح على الخبرات تفسر ب 1 \% من درجة أعراض القلق لدى طلاب الكلية التقنية. 
هـ الوعي بالخبرة الاخلية تفسر 11\% من درجة أعراض القلق لاى طلاب الكلية التقنية. 7. فقدان التركيز وعدم التفاعلية تفسر ، 1\% من درجة أعراض القلق لاى طلاب الكلية التقنية.

V. الفهم الواعي تفسر 1 \% من درجة أعراض القلق لاى طلاب الكلية التقنية.

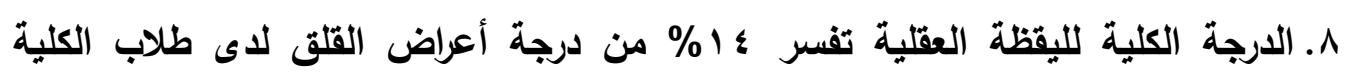

التقنية.

وعليه يمكن بناء نموذج الانحدار على النحو التالي:

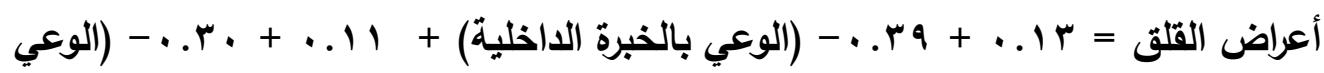

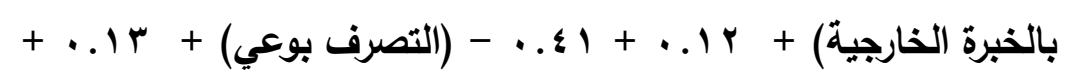

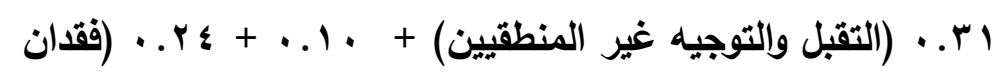

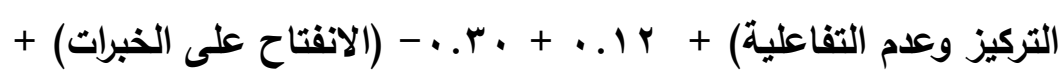

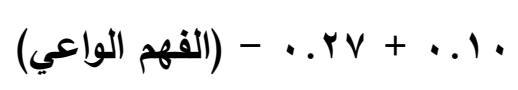

وعليه يصل الباحث إلى الاستنتاجات الآتية:

1. ت تتأثر درجة أعراض القلق لاى طلاب الكلية التقتية بمحافظة بيشة سلباً بالدرجة الكلية لليقظة العقلية بدرجة أكبر من تأثرها بأحد أبعاد اليقظة منفردة.

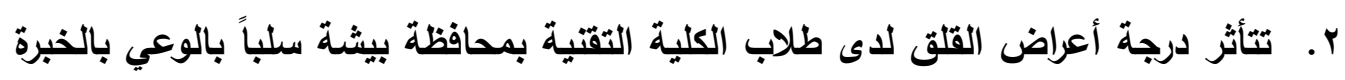

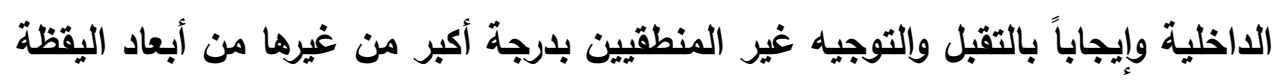
العقلية. r. لا تتأثز درجة أعراض القلث لاى طلاب الكلية التقتية بمحافظة بيشة بنسبية الأفكار كأحد أبعاد اليقظة العقلية. وإجمالاً يرى الباحث أن النتائج الحالية تتسق مع بعضها البعض في الالالة على العوامل

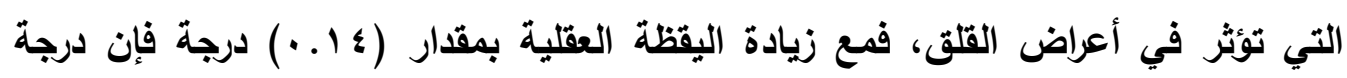
كاملة تقلل من أعراض القلق، وهو ما يؤكد النتائج السابقة التي أشارت إلى وجود علاقة سلبية بين اليقظة العقلية وأعراض القلق، كما كانت الفروق في أعراض القلق بين مرتفعي ومنخفضي اليقظة العقلية لصالح منخفضي اليقظة العقلية. 


\section{توصيات الدراسة:}

ا ـ العمل على دمج تنمية اليقظة العقلية مع فنيات العلاج المعرفي لإدارة الحياة؛ لما لها من أثر فعال في تيسير حدوث عمليات معرفية إيجابية تمثل بدورها متغيرات واقية من احتمالية انتثار القلق لاى طلاب الكلية التقنية.

r. حث أعضاء هيئة التدريس بالكليات التقنية بالمملكة العربية السعودية بوجه عام، وفي بيشة بوجه خاص على تدعيم الجوانب الإيجابية لاى طلاب الجامعة باستمرار، وتحفيزهم نحو استمرارية الاراسة.

r. وضع نظام لاعم وتحفيز طلاب الكلية التقنية نحو امتلاك مجموعة الخصائص الثخصية والاجتماعية الإيجابية؛ والتي تمكنهم من النجاح في الحياة والدراسة بصورة أكثر إيجابية.

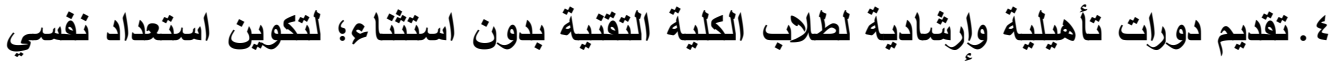
لايهم نحو مواجهة ضغوط الدارسة والحياة، ويالتالي تقليل احتمالية شعورهم بالإحباط الذي قد يسهم في ارتفاع أعراض القلق لايهه. 


\section{مراجع الدراسة:}

\section{أولاً : المراجع العربية.}

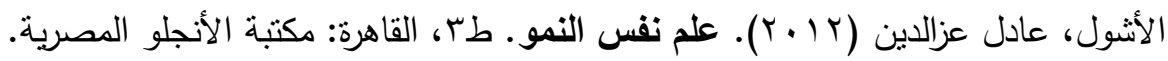

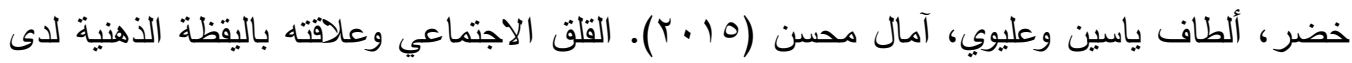

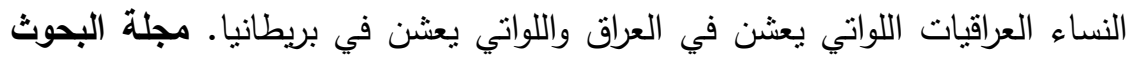

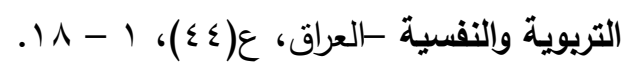

الدويش، سعود فيصل (؟ ( • r). مؤشرات التكيف النفسي والاجتماعي للمراهقين : دراسة وصفية مقارنة في المجتمعين الجزائري والكويتي. دراسات نفسية - مركز البصيرة للبحوث

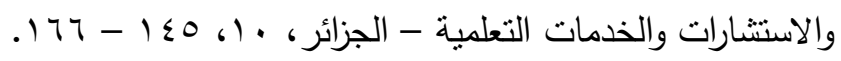

رتيب، ناديا (•(r)، الفوبيا الاجتماعية لدى طلبة الصف الأول الثانوي وعلاقتها بالمعتقدات غير

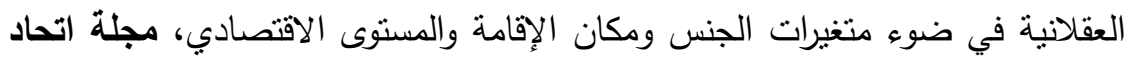

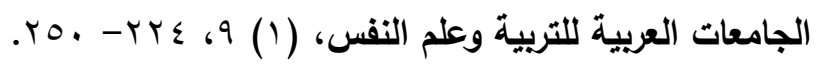

رضوان، سامر جميل (r . . r). الصحة النفسية. عمان: دار المسيرة للنشر والتوزيع والطباعة.

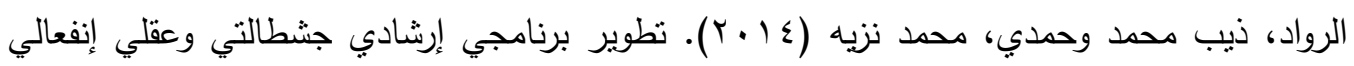

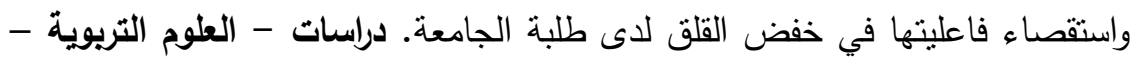

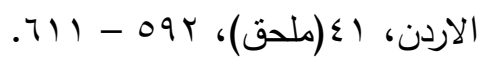

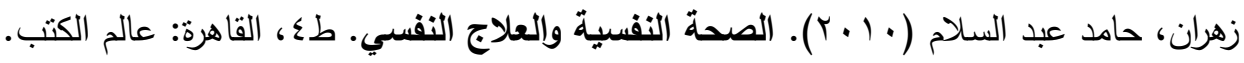

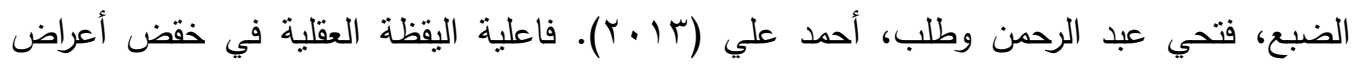

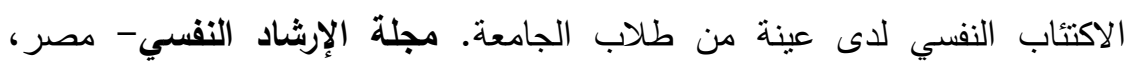

$$
\text { . } v 0-1 ،(r \varepsilon) \varepsilon
$$

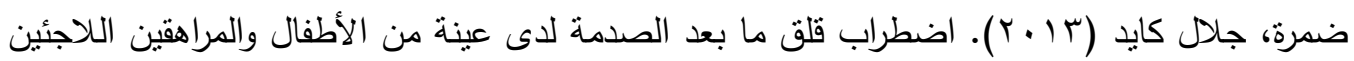

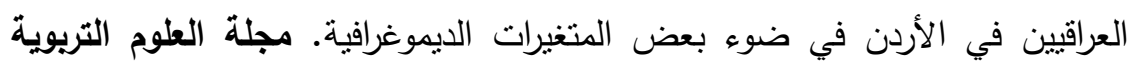

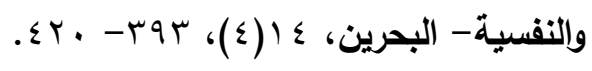

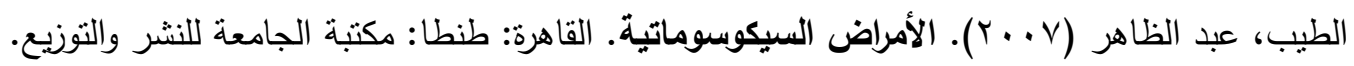

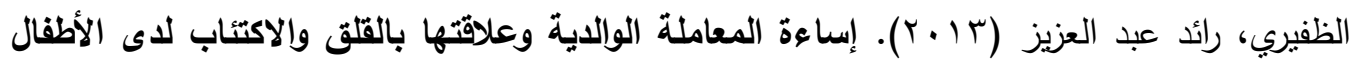
ذوي الإعاقة الذهنية البسيطة بدولة الكويث. رسالة ماجستير غير منشورة، كلية

$$
\text { الدراسات العليا، جامعة الخليج العربي، البحرين. }
$$


العاسمي، رياض نايل (ع 1 ـ r).الثفقة بالذات وعلاقتها ببعض سمات الثخصية لاى عينة من طلاب

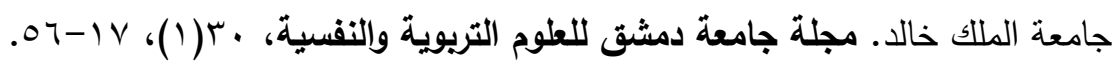
العاسمي، رياض نايل (10 • ب). اليقظة العقلية وسيطاً للعلاقة بين المرونة والاكتئاب والضغوط النفسية

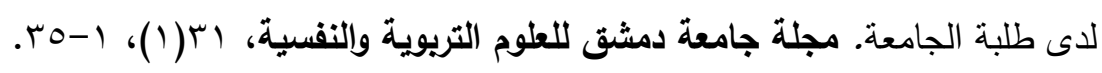
عبد الغفار ، عبد الغفار عبد السلام (999 (9)). الصحة النفسية. طء، القاهرة: مكتبة الفكر العربي. عبد اله، أحلام مهدي (r ( ـ ب). الكفاية الذاتية المدركة وعلاقتها باليقظة الذهنية والوظائف المعرفية لاى طلبة الجامعة. رسالة دكتوراه غير منشورة، كلية التربية، جامعة بغداد، العراق.

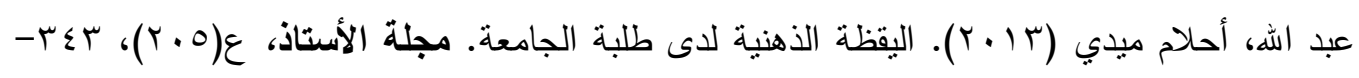
.

عسيري، عبد الله إبراهيم (V. . . . . مستويات القلق لاى طلاب الجامعة. رسالة ماجستير (غير منشورة)، كلية الدراسات العليا، أكاديمية نايف للعلوم الأمنية، السعودية.

علي، هبه محمود (Y Y.r). سمات الشخصية الخمس الكبرى وأساليب مواجهة المشقة كمنبئات بأعراض الاكتئاب والقلق لاى طلاب الجامعة. رسالة دكتوراه غير منشورة، كلية الآداب، جامعة حلوان.

قزاز ، إمام محمد وعبيد، محمود (0 1 • ). مظاهر القلق لدى طلبة تخصص التربية الخاصة في جامعة الملك عبد العزبز قبيل فصل التربية العملية وارتباطها ببعض المتغيرات. مجلة المعهد

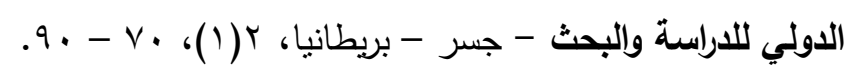

كفافي، علاء الدين (ع ا • Y). الجديد في الصحة التفسية. القاهرة: مكتبة النهضة العربية. محمد، صلاح الدين عراقي (ع ( ب). الحساسية للقلق وعلاقتها بكل من تتظيم الانفعال وأعراض القلق

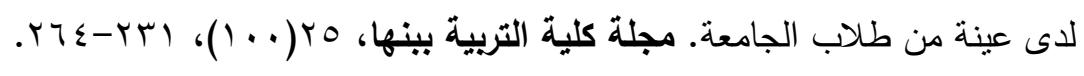

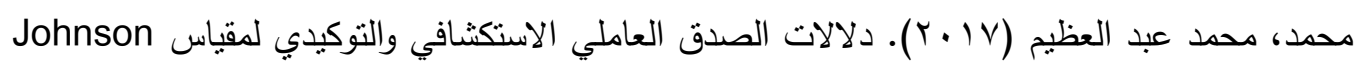

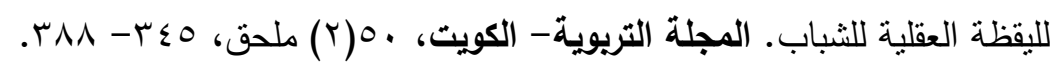
محمود، إيمان عبد الوهاب (Y Y (Y). مستوى القلق لدى أمهات الأطفال المعاقين ذهنيا و علاقته بنوع

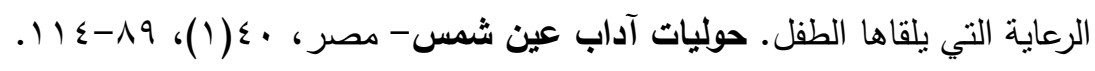

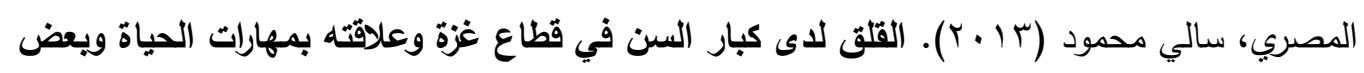
المتغيرات. رسالة ماجستير غير منشورة، كلية التربية، الجامعة الإسلامية بغزة، فلسطين.

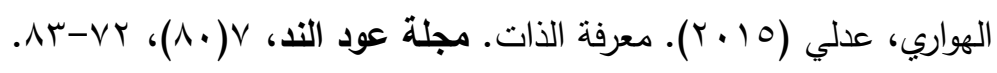




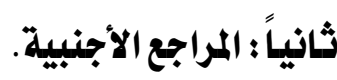

Baer .R.A.\& smith, G .t.; Hopkins .S .J \& kritemeyer, J (2006). Using selfreport assessment methods to explore facets of mindfulness. Previn .

Bernay, R. (2009).Using mindfulness to slow down in order to speed up progress for children with special needs. Double Blind Peer Reviewed Proceedings of the Making Inclusive Education, Sept. 28-30, Wellington.

Browen, P. (2011). Teaching mindfulness to individuals with schizophrenia. Unpublished Doctoral Dissertation, the University of Montana, Missoula, MT.

Brown, K.\& Ryan, R. (2007). Minfulness: theoretical foundations and evidence for its salutary effects. Psychological Inquiry, 14, 71-76.

Essaua, A., Olayab, B., Pashad, G., O’Callaghana, J.\& Braya, D. (2012). The structure of anxiety symptoms among adolescents in Iran: A confirmatory factor analytic study of the Spence Children's Anxiety Scale. Journal of Anxiety Disorders, 26 (3) 871- 878.

Grow, J., Collins, s., Harrop, E.\& Marlatt, G. (2015). Enactment of home practice following mindfulness-based relapse prevention and its association with substance-use outcomes. Addictive Behaviors, 40(1), 16-20.

Hasker, M. (2010). Evaluation Of The Mindfulness-Acceptance-Commitment (Mac) Approach For Enhancing Athletic Performance. Unpublished Doctoral Dissertation. Indiana University of Pennsylvania, U.S.A.

Lackner, C., Marshall, J., Santesso, D., Dywan, J.\& Terrance Wade. T., Segalowitz, S. (2014). Adolescent anxiety and aggression can be differentially predicted by electrocortical phase reset variables. Brain and Cognition, 89 (1), 90-98.

Langer, E. (1992). Minffulness. New York: Addison Wesley publishing.

Leigh J., Bowen S.\&, Marlatt, G. (2005). Spirituality, mindfulness and substance abuse. Addict Behavior, 30(7), 1335-1341.

Mace, C. (2008). Mindfulness and mental health: therapy, theory and science. London: Routledge Taylor \& Francis Group.

Michail, M.\& Birchwood, M. (2014). Social anxiety in first-episode psychosis: The role of childhood trauma and adult attachment. Journal of Affective Disorders, 163(1), 102-109.

Neff, D. (2003).The development and validation of a scale to measure selfcompassion. Self and Identity, 2, 233-250.

Niles, N., Dour, H., Stanton, L., Roy-Byrne, P., Steinc, M., Sullivan. G., Sherbourne, D., Rose, R., Craske, M. (2015). Anxiety and depressive symptoms and medical illness among adults with anxiety disorders, Journal of Psychosomatic Research, 78 (1), 109-115. 
Panayiotou, G., Karekla, M.\& Mete, I. (2014). Dispositional coping in individuals with anxiety disorder symptomatology: Avoidance predicts distress. Journal of Contextual Behavioral Science, 3(3), 314-321.

Pepping, C.\& Duvenage, M. (2016).The origins of individual differences in dispositional mindfulness. Personality and Individual Differences, 93(1), 130-136.

Sangeetha, E. (2014). An exploration of mindfulness as a stress reduction prevention for adolescents. Ed. D., California State University.

Shorey, C., Elmquist, J., Clevenger, W., Gawrysiak, M., Anderson, S.\& Stuart, G. (2016). The relationship between dispositional mindfulness, borderline personality features, and suicidal ideation in a sample of women in residential substance use treatment. Psychiatry Research, 238, 122-128.

Uchida, M. (2014). Further evidence that severs cores in the aggression/ anxiety-depression /attention subscales of child behavior checklist (severe dysregulation profile) can screen for bipolar disorder symptomatology: a conditional probability analysis. Journal of Affective Disorders, 165(1), 81-86.

Uludag, O. (2014). Fair and Square: How does Perceptions of Fairness is Associated to Aggression?. Procedia-Social and Behavioral Sciences, 145(3), $504-508$.

Weissbecker, I., Salmon, P., Studts, L., Floyd, R., Dedert, A. \& Sephton, E. (2002). Mindfulness-based stress reduction and sense of coherence among women with fibromyalgia. Journal of Clinical Psychology in Medical Settings, 9(4), 297-307.

Witkiewitz, K., Bowen, S., Douglas, H.\& Hsu, S. (2012). Mindfulness-based relapse prevention for substance craving. Addict Behav. 38(2), 15631571. 